\title{
The conserved dileucine- and tyrosine-based motifs in MLV and MPMV envelope glycoproteins are both important to regulate a common Env intracellular trafficking
}

Vincent Blot* $\uparrow 1,3,4,5,6$, Sandra Lopez-Vergès ${ }^{\dagger 2,3,4,5}$, Marie Breton $1,3,4,5$, Claudine Pique P,3,4,5, Clarisse Berlioz-Torrent $^{2,3,4,5}$ and MariePierre Grange $e^{1,3,4,5}$

\author{
Address: ${ }^{1}$ Institut Cochin, DépartementBiologie Cellulaire, Paris, F-75014 France, ${ }^{2}$ Institut Cochin, DépartementMaladies Infectieuses, Paris, F- \\ 75014 France, ${ }^{3}$ Inserm, U567, Paris, F-75014 France, ${ }^{4}$ CNRS, UMR 8104, Paris, F-75014 France, ${ }^{5}$ Université Paris 5, Faculté de Médecine René \\ Descartes, UMR3, Paris, F-75014 France and 'Weill Medical College of Cornell, Biochemistry Dept, New York, NY10021 USA \\ Email: Vincent Blot* - Vincent.blot@normalesup.org; Sandra Lopez-Vergès - slopez@cochin.inserm.fr; Marie Breton - breton@cochin.inserm.fr; \\ Claudine Pique - pique@cochin.inserm.fr; Clarisse Berlioz-Torrent - berlioz@cochin.inserm.fr; Marie-Pierre Grange - marie- \\ pierre.grange@wanadoo.fr \\ * Corresponding author †Equal contributors
}

Published: 15 September 2006

Retrovirology 2006, 3:62 doi:10.1186/1742-4690-3-62

This article is available from: http://www.retrovirology.com/content/3/I/62

(C) 2006 Blot et al; licensee BioMed Central Ltd.

This is an Open Access article distributed under the terms of the Creative Commons Attribution License (http://creativecommons.org/licenses/by/2.0), which permits unrestricted use, distribution, and reproduction in any medium, provided the original work is properly cited.
Received: 20 July 2006

Accepted: 15 September 2006

\begin{abstract}
Background: Retrovirus particles emerge from the assembly of two structural protein components, Gag that is translated as a soluble protein in the cytoplasm of the host cells, and Env, a type I transmembrane protein. Because both components are translated in different intracellular compartments, elucidating the mechanisms of retrovirus assembly thus requires the study of their intracellular trafficking.
\end{abstract}

Results: We used a CD25 (Tac) chimera-based approach to study the trafficking of Moloney murine leukemia virus and Mason-Pfizer monkey virus Env proteins. We found that the cytoplasmic tails (CTs) of both Env conserved two major signals that control a complex intracellular trafficking. A dileucine-based motif controls the sorting of the chimeras from the trans-Golgi network (TGN) toward endosomal compartments. Env proteins then follow a retrograde transport to the TGN due to the action of a tyrosine-based motif. Mutation of either motif induces the mis-localization of the chimeric proteins and both motifs are found to mediate interactions of the viral CTs with clathrin adaptors.

Conclusion: This data reveals the unexpected complexity of the intracellular trafficking of retrovirus Env proteins that cycle between the TGN and endosomes. Given that Gag proteins hijack endosomal host proteins, our work suggests that the endosomal pathway may be used by retroviruses to ensure proper encountering of viral structural Gag and Env proteins in cells, an essential step of virus assembly. 


\section{Background}

Retroviruses are surrounded by a lipid envelope acquired by the virus from cellular membranes through a budding process. Anchored in this lipid envelope are the viral envelope glycoproteins (Env), which are heterodimers between a transmembrane subunit (TM) and a covalently or non-covalently attached extracellular subunit (named SU for surface). Both subunits emerge from the cleavage of a single type- 1 transmembrane envelope glycoprotein precursor (for review on retrovirus structural protein synthesis, see [1].

The Gag proteins precursor, simply referred to here as $\mathrm{Gag}$, is the only viral structural protein that is both necessary and sufficient to produce virus-like particles (VLPs) by budding into the extracellular medium, even in the absence of Env [2,3]. However, VLPs devoid of Env are non infectious since Env glycoproteins are necessary for the attachment of the virions to their receptor(s) and subsequent fusion of viral and target cell membranes leading to virus entry. The Env precursor is co-translationally anchored in the membrane of the endoplasmic reticulum and then follows the trafficking of transmembrane and soluble proteins along the secretory pathway. By contrast, Gag is synthesized by free ribosomes in the cytosol, before being able to bind to internal membranes through signals in its amino-terminus. Given that both structural components are being translated in different subcellular compartments, some specific mechanisms must account for their encounter at the site of virus assembly and budding.

Studying the precise steps of the intracellular trafficking of envelope glycoproteins should then bring some understanding as to how they encounter Gag in cells. In the case of human immunodeficiency virus (HIV) Env, it has been shown that the cytoplasmic tail (CT) of the TM subunit contains several motifs that regulate Env trafficking. A tyrosine-based motif (Yxx $\Phi$ where $\Phi$ is a bulky hydrophobic amino-acid) has been implicated in Env endocytosis after its arrival at the cell surface by mediating interaction with the AP-2 clathrin adaptor complexes [4-7]. A dileucine-based motif (consensus sequence LL or L $\Phi$ ) has also been shown to control some post-Golgi trafficking step by recruiting the AP- 1 adaptor complexes [5,8]. Finally, HIV Env is also able to undergo a retrograde endosome to trans-Golgi network (TGN) route through the interaction of a diaromatic YW motif, located in the cytoplasmic domain of Env, with the TIP47 protein [9].

The intracellular transport of HIV Env glycoproteins has been extensively examined, however little is known about the trafficking of envelope glycoproteins of retroviruses that do not belong to the lentivirus genus. The cytoplasmic tails of human T-cell leukemia virus (HTLV) and Moloney murine leukemia virus (MLV) Env possess a tyrosine-based motif that is able to target them to the basolateral membrane of polarized MDCK cells [10]. Dileucine- and tyrosine-based motifs in the CT of bovine leukemia virus (BLV) Env are responsible for low surface expression of Env, although the details of Env intracellular trafficking were not elucidated [11]. We have shown in a previous study that engrafting the CTs of different retrovirus Env to the carboxy-terminus of the CD25 reporter molecule leads to specific intracellular trafficking pathways of the resulting chimeras [12]. Indeed, HTLV, BLV and Rous sarcoma virus (RSV) CD25 chimeras are endocytosed after reaching the cell surface, whereas chimeras containing either MLV or Mason-Pfizer monkey virus (MPMV) CT appeared mainly retained inside the cells in a Rab6-positive Golgi or post-Golgi compartment.

In this study, we aimed to precisely define the intracellular routes followed by MLV and MPMV envelope glycoproteins. Using the same CD25 chimera-based approach, we found that these proteins accumulated in the TGN as a result of a dynamic transport involving a retrograde route from endosomes to the TGN. A membrane proximal dileucine-based motif and a more distal tyrosine-based motif conserved between both CTs governed this peculiar trafficking. The dileucine-based motif is implicated in the sorting of the chimeras at the level of the TGN, whereas the tyrosine-based motif is required in the retrograde transport step. We also documented that both motif mediate in vitro interaction with clathrin adaptors, linking their functional role in Env trafficking with their capacity to physically interact with cellular trafficking machineries.

\section{Results \\ CD25-MuLV and CD25-MPMV chimera accumulated in the TGN}

We have previously shown that engrafting the cytoplasmic tail of either MLV or MPMV envelope glycoprotein to the carboxyl-terminus of the $\mathrm{CD} 25$ protein induced the intracellular retention of the resulting chimeras [12]. Both chimeras colocalized at steady state with the small GTPase Rab6, a protein distributed between the Golgi apparatus and the TGN $[13,14]$.

To define more precisely the intracellular site of accumulation of the chimeras, we treated transiently transfected HeLa cells with cycloheximide, which acted by preventing new synthesis of proteins. CD25-MuLV and CD25-MPMV chimeras appeared then mainly concentrated in a tubularshaped perinuclear compartment as well as in dots dispersed throughout the cytoplasm (figure 1, CD25 panels) whereas the control CD25 protein accumulated at the cell surface (data not shown and [12]).

We then compared the distribution of the chimeras with those of different intracellular markers: the Mannose-6- 
A.
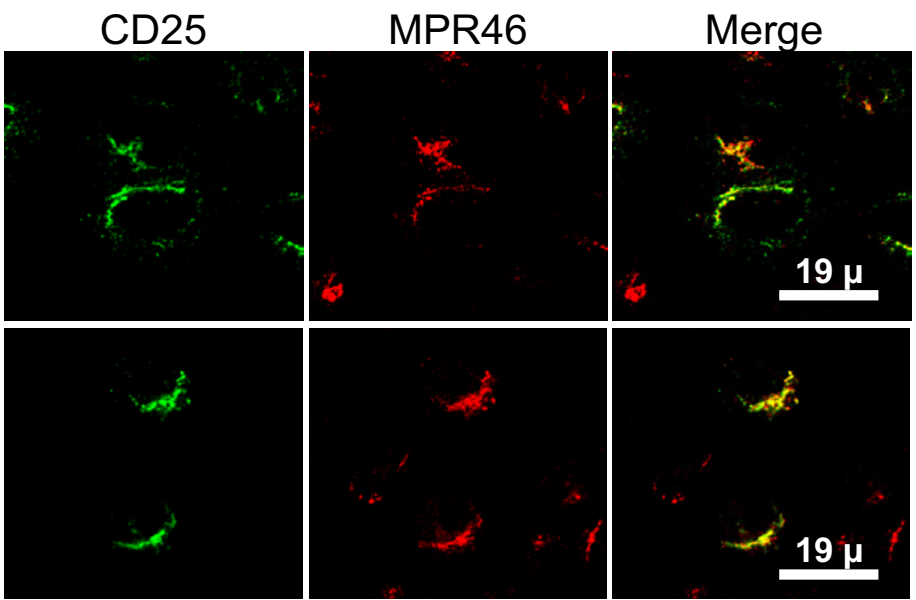

B.
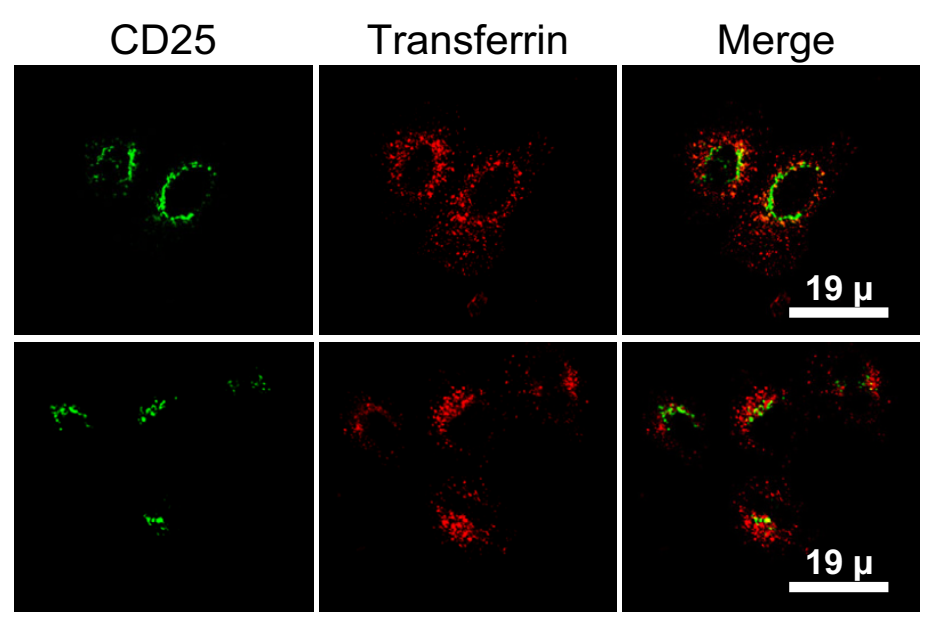

C.
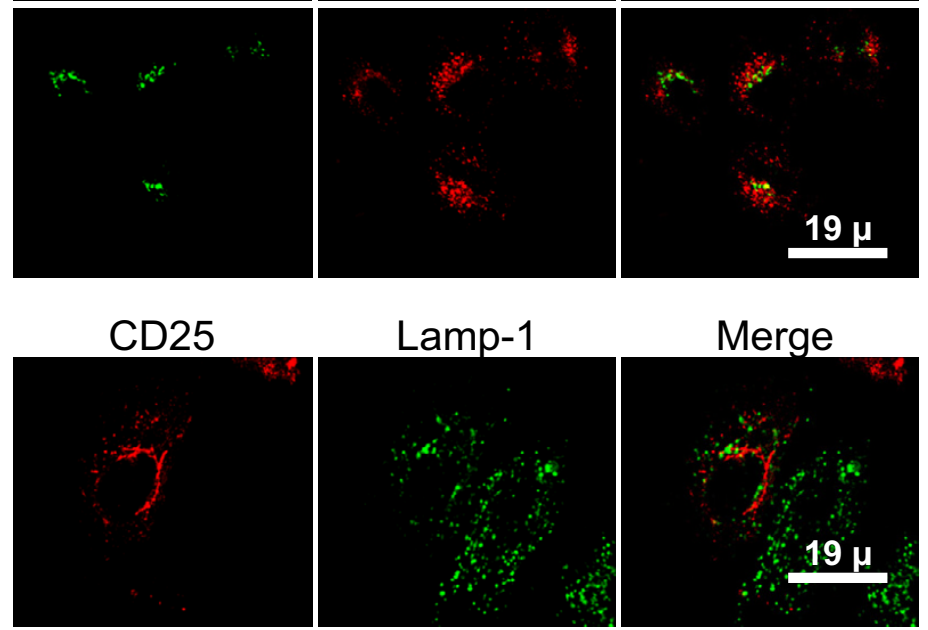

CD25-MuLV WT

CD25-MPMV WT
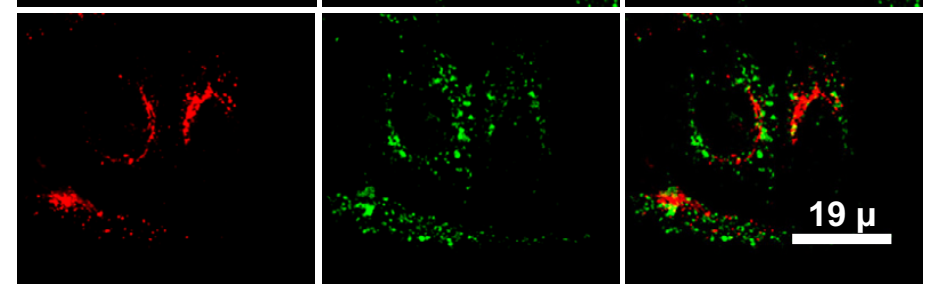

\section{Figure I}

CD25-MLV and CD25-MPMV accumulate in the TGN. Forty-eight hours after transfection with the appropriate chimera cDNA, cells were treated with cycloheximide for 3 hours prior to fixation and staining. A. Co-staining of CD25 chimeras and Mannose 6-phosphate receptor of $46 \mathrm{kDa}$ (MPR46), a protein that accumulates in the TGN at steady state. B. Co-staining of CD25 chimeras and internalized Cy3-conjugated tranferrin revealing the early/recycling endosomes. C. Co-staining of CD25 chimeras and Lampl, a protein resident of the lysosomes. 


\title{
A. Wild type CD25 chimeric proteins
}

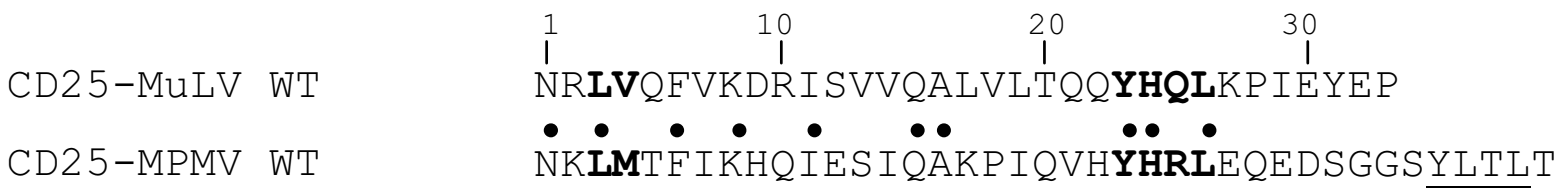

\section{B. Mutant CD25 chimeric proteins}

\author{
CD25-MuLV L3S \\ CD25-MuLV Y23S \\ CD25-MuLV L3S/Y23S \\ $\begin{array}{ll}\text { CD25-MPMV L } 3 S \\ \text { CD25-MPMV } & \text { Y23S } \\ \text { CD25-MPMV } & \text { Y35S } \\ \text { CD25-MPMV } & \text { L3S/Y23S }\end{array}$
}

NRS్

NRIVQFVKDRISVVQALVLTQQSHQLKP IEYEP

NR $\underline{\mathbf{S} V Q F V K D R I S V V Q A L V L T Q Q \underline{\mathbf{S}} H Q L K P I E Y E P}$

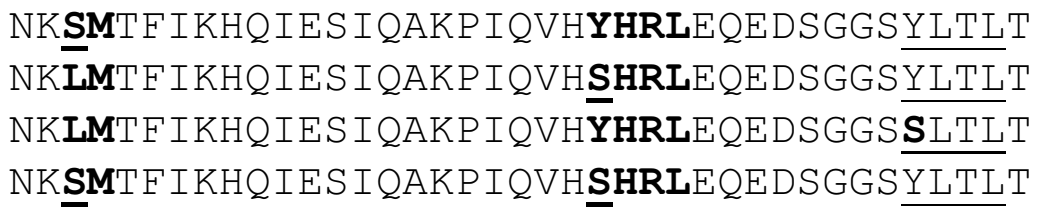

Figure 2

Sequences of wild type and mutant MLV and MPMV cytoplasmic tails. A. The 10 amino acids conserved between MLV and MPMV cytoplasmic tails (CT) are noted - Bold letters indicate the position of the conserved dileucine- and tyrosinebased motifs, whereas underlined letters indicate the position of the extra tyrosine-based motif in MPMV CT. B. Sequences of the mutated CD25 chimeras that we used in this study. The mutants are named CD25-retrovirus $X$ amino acid position $Z$, where $X$ and $Z$ are the wild-type and mutant amino-acids, respectively. The amino-acid position $I$ corresponds to the first residue of the corresponding viral CT.

phosphate receptor of $46 \mathrm{kDa}$ (MPR46) that cycles between the TGN and late endosomes and is mainly localized in the TGN at steady state [15], internalized cyanin3conjugated transferrin that reveals the general early and recycling endosomal pathway and Lamp1, a marker of lysosomes [16]. CD25-MLV and CD25-MPMV did not colocalize with either endocytosed transferrin or Lamp1, indicating that they do not accumulate in the endocytic pathway (figure 1B and 1C). By contrast, both proteins showed extensive colocalization with MPR46 revealing that their intracellular compartment of retention is the TGN (figure 1A).

A dileucine- and a tyrosine-based motifs are both required for the TGN localization of CD25-MuLV and CD25-MPMV chimeras

To define the motifs in MLV and MPMV cytoplasmic tails important for this peculiar localization, we compared their primary sequences (figure 2A). The two sequences shared 10 amino acids conserved in position, amongst which two clusters fit potential conventional sorting signals: the dileucine-based motifs ${ }^{3} \mathrm{LV}^{4} /{ }^{3} \mathrm{LM}^{4}$ and the tyro- sine-based motif ${ }^{23} \mathrm{YHQL}^{26} /{ }^{23} \mathrm{YHRL}^{26}$ in MLV and MPMV sequences respectively (where 1 is the position of the first amino-acid in each viral cytoplasmic tail). MPMV cytoplasmic tail possesses a second tyrosine-based motif $\left({ }^{35} \mathrm{YLTL}^{38}\right)$ that is not conserved in the MLV cytoplasmic domain.

To investigate the implication of these putative sorting motifs in the trafficking of the chimeras, we produced a diversity of point mutations in the cytoplasmic tails by site-directed mutagenesis (figure 2B). We then analyzed the effects of these mutations on the intracellular localization of the resulting mutated chimeras. Mutation of the tyrosine 23 to serine in either MLV and MPMV CT provoked a relocalization of the chimeras to peripheral dots dispersed throughout the cytoplasm that do not colocalize with MPR46 (figure 3A). By contrast, mutation of the distal ${ }^{35}$ YLTL $^{38}$ tyrosine-based motif in MPMV cytoplasmic tail had no effects (figure 3A lower panels). Changing the leucine 3 into a serine resulted in a partial shift of the localization of the chimeras from the TGN to peripheral dots and the mutated chimeras still colocalized to some 
A.

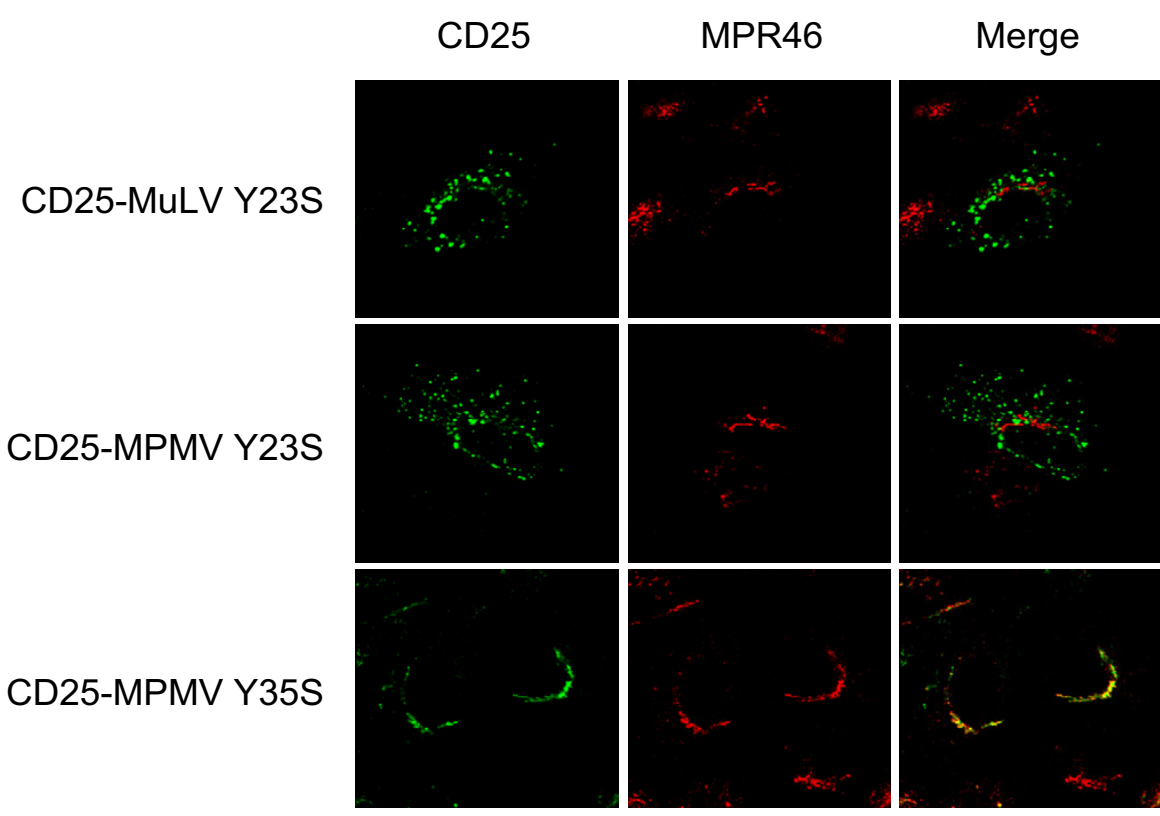

B.

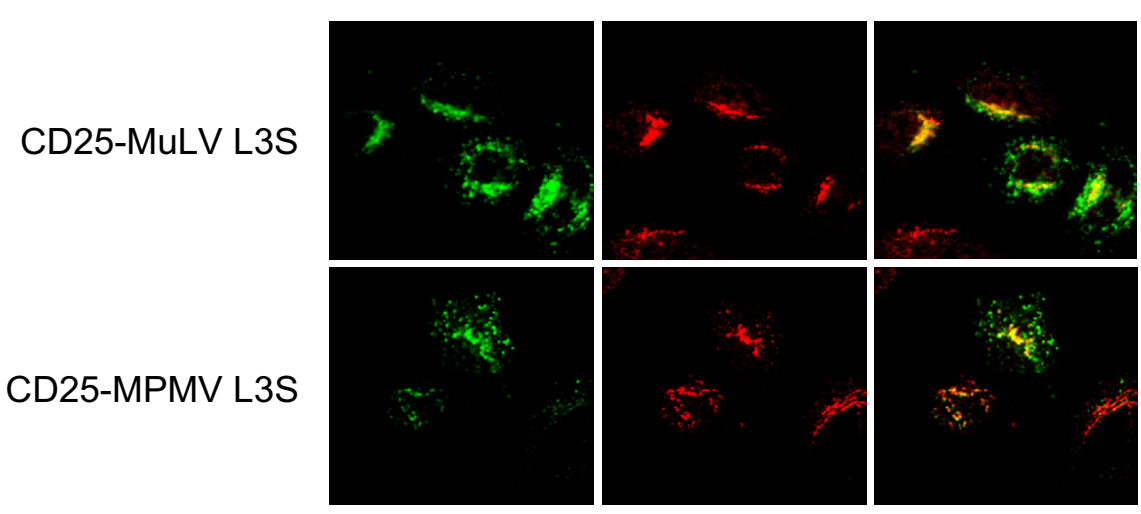

C.

CD25-MuLV L3S/Y23S
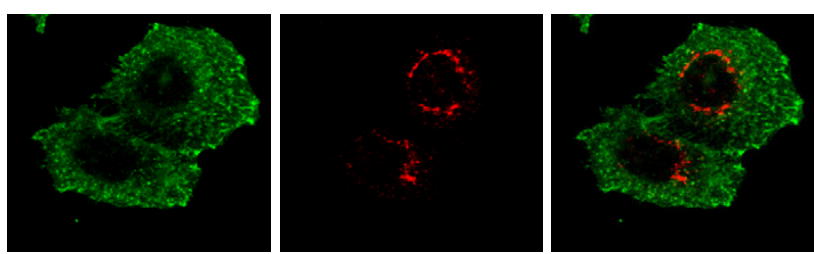

CD25-MPMV L3S/Y23S
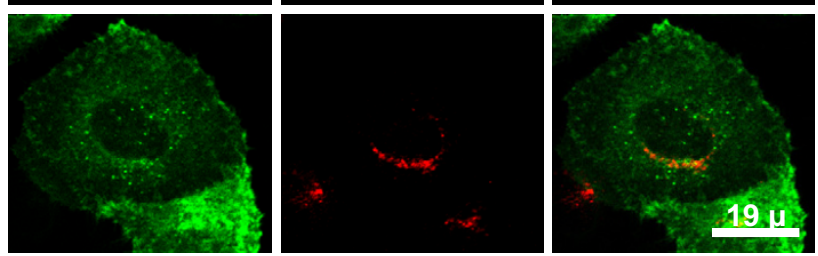

\section{Figure 3}

Mutation of either the dileucine- or the tyrosine-based motifs affect the TGN localization of CD25 chimeras. Forty-eight hours after transfection with the appropriate chimera cDNA, cells were treated with cycloheximide for 3 hours prior to fixation and permeabilization. Co-stainings of MPR46 and chimeras bearing either (A) the Y23S or the Y35S mutation, (B) the L3S mutation, or (C) both L3S and Y23S mutations. 
extent with MPR46 (figure 3B). Finally, MLV and MPMV chimeras mutated on both leucine 3 and tyrosine 23 mainly accumulated at the plasma membrane (figure 3C), thus behaving as the control CD25.

Thus, extensive localization of the CD25-MLV and the CD25-MPMV chimeras in the TGN required both the dileucine-based motif in position 3 and the tyrosinebased motif in position 23. By contrast, the tyrosine-based motif in position 35 of the MPMV cytoplasmic tail does not play a significant role in the TGN localization of the protein.

\section{CD25-MLV and CD25-MPMV with mutated dileucine- or tyrosine-based motifs accumulate in different endocytic compartments}

We then assess whether the changes in localization of the CD25-MLV and CD25-MPMV chimeras that we observed after mutating either the dileucine- or the tyrosine-based motif revealed a relocalization of the protein in endocytic compartments. We used internalized transferrin as a marker of early/recycling endosomes, Lamp1 as a marker of lysosomes and dextran internalized for 30 minutes and chased for an equivalent amount of time to reveal late endosomal compartments.

Chimeras with mutations in the dileucine-based motif showed partial colocalization with the three markers of the endosomal pathway (figure 4A, 4B and 4C, arrows). Colocalization of chimeras with Lamp1, however, is weaker than with endocytosed transferrin or dextran. Thus, the fraction of L3S mutated chimeras that is delocalized from the TGN is redistributed throughout the endosomal pathway. By contrast, chimeras bearing the Y23S mutation did not colocalize with either transferrin or Lamp1 (figure 5A and 5C), indicating that they are absent from early/recycling endosomes or lysosomes. However, these mutant proteins did colocalize to some extent with internalized and chased dextran (figure 5B, arrows). Thus, mutation of the tyrosine-based motif in position 23 induced the relocalization of both CD25-MLV and CD25MPMV chimeras in non well-defined late endosomal compartments.

\section{Internalization of chimeras from the plasma membrane is} mainly driven by the tyrosine-based motif in position 23

That the chimeras are mainly detected in intracellular sites at steady state could either reflect an active retention of the proteins within the cells or their slow recycling to the plasma membrane followed by their rapid internalization. We thus wanted to determine whether the chimeras could be endocytosed from the plasma membrane. To that extent, we compared the abilities of the different WT and mutant chimeras to allow uptake of monoclonal antiCD25 antibody. Transiently-transfected HeLa cells were then incubated for $30 \mathrm{~min}$ at $4^{\circ} \mathrm{C}$ with anti-CD25 antibody and shifted or not at $37^{\circ} \mathrm{C}$ for 30 additional minutes. For each chimera, we then compared the amount of anti-CD25 antibody remaining at the cell surface after 30 minutes at $37^{\circ} \mathrm{C}$ relative to the amount of anti-CD25 at the cell surface at time 0 .

After 30 minutes, approximately $50 \%$ of bound antiCD25 antibody was internalized in cells expressing either CD25-MLV or CD25-MPMV chimeras. This is similar to the amount of CD25 internalized in cells expressing CD25-TFR, a control chimera containing the well defined YRTF endocytic signal of the transferrin receptor (figure $6 \mathrm{~A}$ and $6 \mathrm{~B}$ ). By contrast, the CD25 control protein that lacks specific internalization signals or viral cytoplasmic tail does not allow measurable uptake of anti-CD25 antibody. This indicates that viral cytoplasmic tails in CD25MLV and CD25-MPMV chimeras contain specific internalization signals.

Mutation of the dileucine-based motifs in MLV or MPMV chimera did not impair the capacity of the proteins to mediate specific uptake anti-CD25 antibody (fig 6A and $6 \mathrm{~B}$; L3S). By contrast, chimeras bearing the Y23S mutation had a decreased ability to allow anti-CD25 antibody retrieval from the cell surface (figure 6A and 6B). Chimeras bearing both L3S and Y23S mutations behave like the single Y23S mutant indicating that the lack of detectable effects of the single L3S mutation was not due to redundancy with the Y23 tyrosine-based motif.

Altogether, these results indicate that CD25-MLV and CD25-MPMV chimeras are internalized from the plasma membrane, and that the tyrosine-based motif in position 23 acts as their main endocytosis signal.

\section{The tyrosine-based motif in position 23 drives a retrograde transport step toward the TGN}

The steady state TGN localization of proteins like MPRs, furin or TGN38 is the results of a complex trafficking involving a retrograde transport from endosomes to the TGN $[15,17]$. We thus assessed the capacity of MLV and MPMV cytoplasmic tails to target the chimeras to the TGN following their internalization in endosomes.

One hour after their internalization from the cell surface, anti-CD25 antibodies taken up by either the CD25-MLV or CD25-MPMV chimera were found concentrated in a perinuclear region of the cells (figure 7A). Both chimeras then extensively colocalized with MPR46, indicating that they reached the TGN (figure 7A). By contrast, anti-CD25 taken up by the control CD25-TFR construct that follows the recycling pathway of the transferrin receptor did not colocalize with MPR46 (figure 7A), indicating that both MLV and MPMV cytoplasmic tails contain specific infor- 
A.

CD25-MuLV L3S

CD25-MPMV L3S
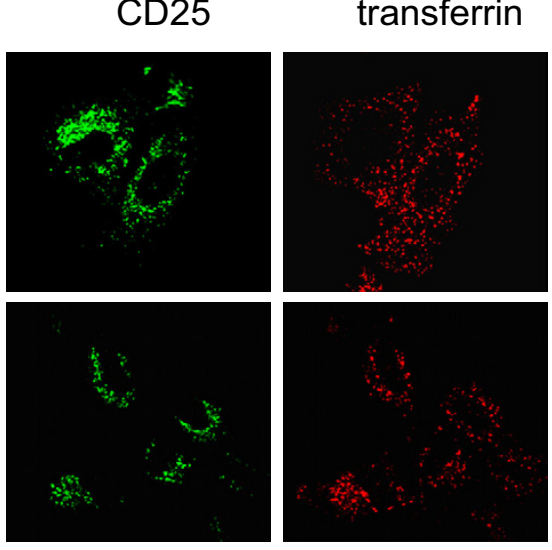

transferrin

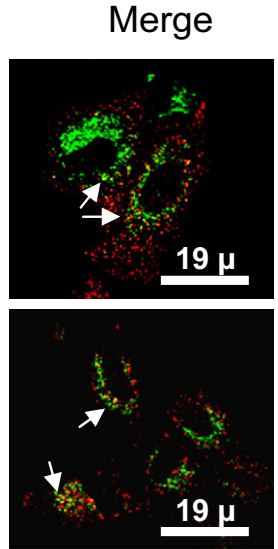

B.

CD25-MuLV L3S
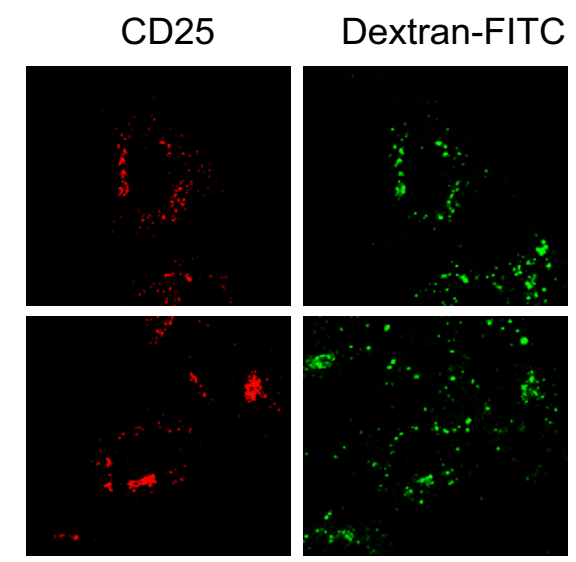

CD25-MPMV L3S

C.

CD25-MuLV L3S
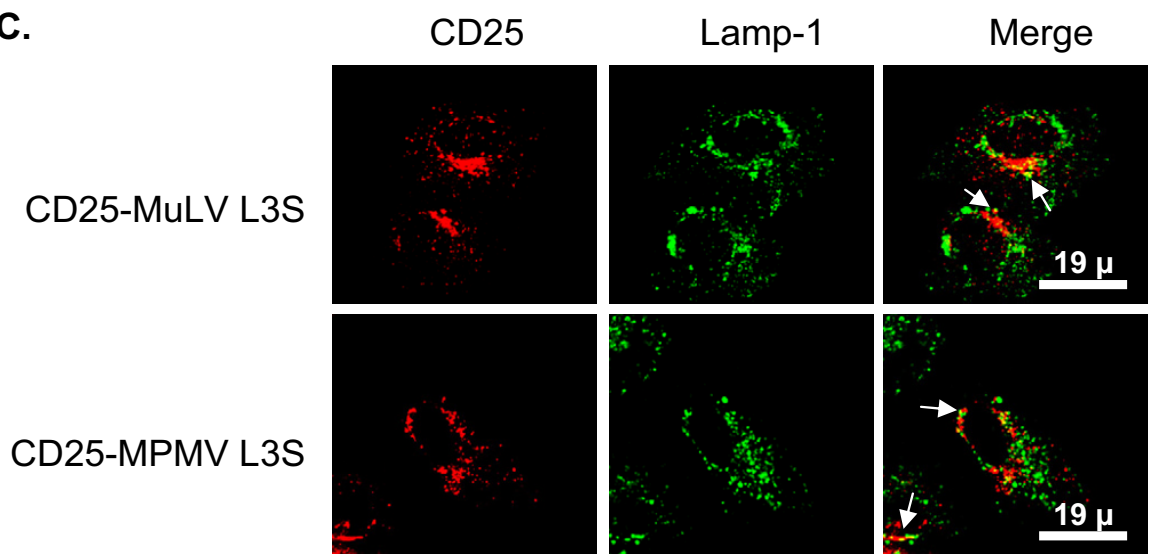

CD25-MPMV L3S

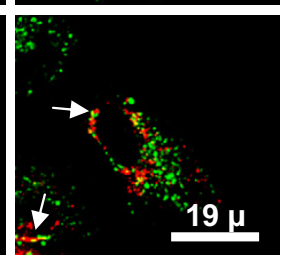

\section{Figure 4}

Chimeras bearing the L3S mutation are relocated throughout the endosomal pathway. Forty-eight hours after transfection with the L3S mutant chimeras CDNA, HeLa cells were treated with cycloheximide for 3 hour prior to fixation and permeabilization. A. Co-staining of $\mathrm{L} 3 \mathrm{~S}$ mutant chimeras and internalized Cy3-conjugated transferrin revealing the early/recycling endosomes.B. Cells were allowed to take up FITC-conjugated dextran for $30 \mathrm{~min}$. Cells were then extensively washed, and dextran was chased for another $30 \mathrm{~min}$ prior to fixation and CD25 staining. FITC-dextran thus revealed some late endosomal compartment. C. Co-staining of CD25 chimeras and LampI, a protein resident of the lysosomes. 
A.

CD25-MuLV Y23S

CD25-MPMV Y23S

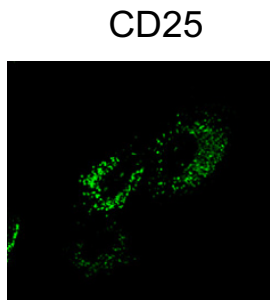

Transferrin
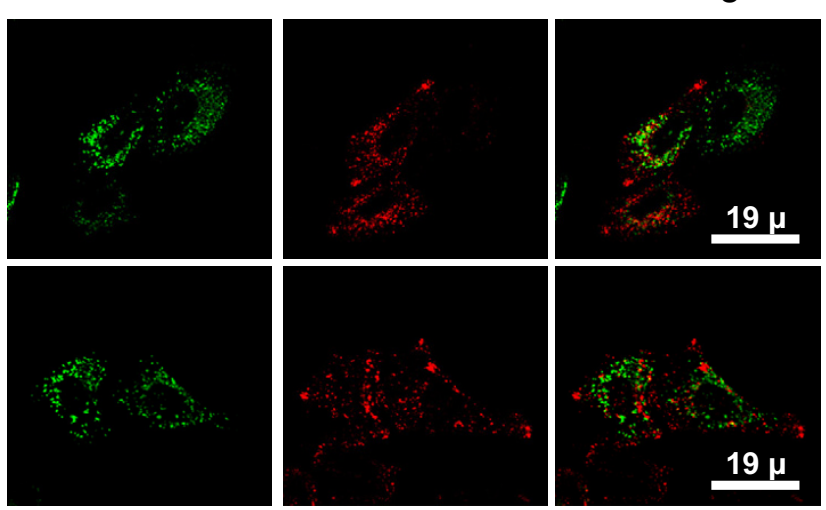

B.

CD25-MuLV Y23S

CD25-MPMV Y23S

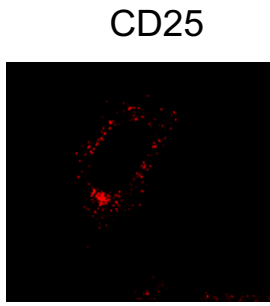

Dextran-FITC
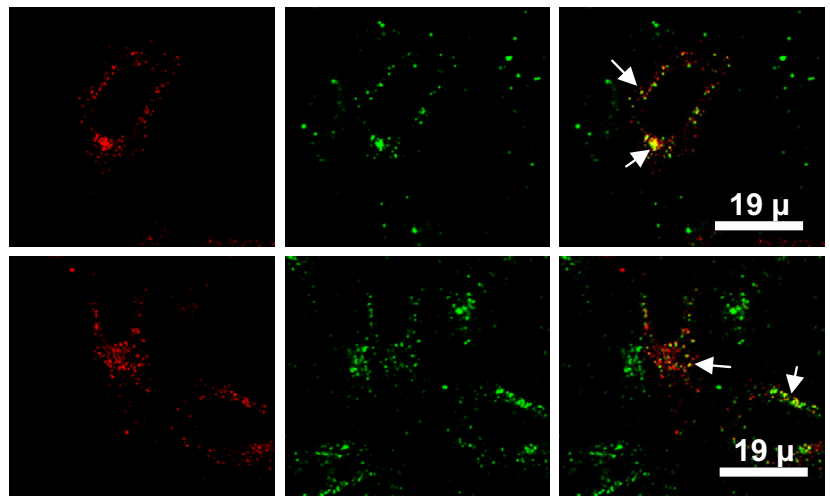

C.

CD25-MuLV Y23S

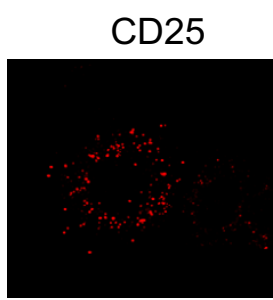

Lamp-1
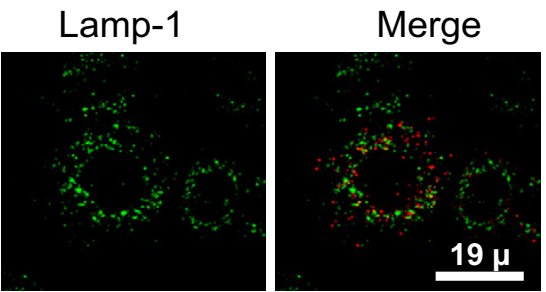

CD25-MPMV Y23S
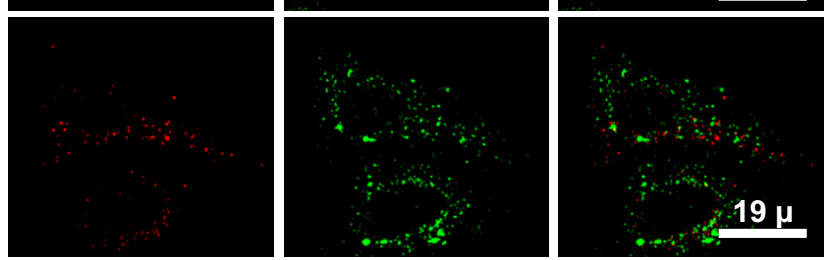

\section{Figure 5}

Chimeras bearing the Y23S mutation are mainly relocated to a late endosomal compartment. Forty-eight hours after transfection with the Y23S mutant chimeras cDNA, HeLa cells were treated with cycloheximide for 3 hour prior to fixation and permeabilization. A. Co-staining of Y23S mutant chimeras and internalized Cy3-conjugated transferrin revealing the early/recycling endosomes.B. Before fixation, cells were allowed to take up FITC-conjugated dextran for 30 min. The cells were then extensively washed, and dextran was chased for another 30 min prior to fixation thus accumulating in late endosomal compartments. C. Co-staining of CD25 chimeras and LampI, a protein resident of the lysosomes. 
A.

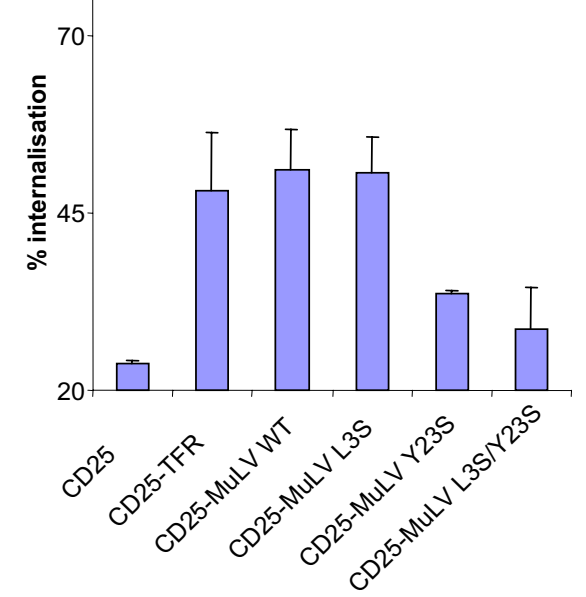

B.

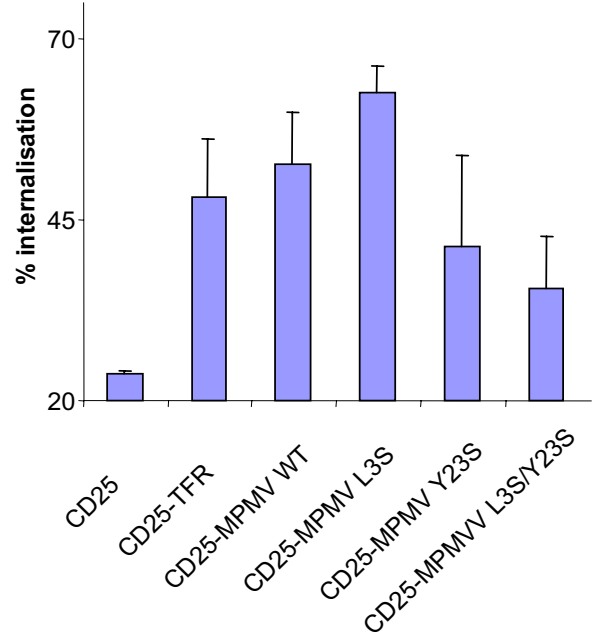

Figure 6

Effects of the L3S and/or Y23S mutations on the chimeras ability to be retrieved from the plasma membrane. HeLa cells were cotransfected with GFP vector and with the appropriate A MLV or B MPMV chimera CDNA.

Cells were then incubated for I hour at $4 \mathrm{C}$ with anti-CD25 antibody before being either shifted for $30 \mathrm{~min}$ at $37^{\circ} \mathrm{C}$ or not. Anti-CD25 stainings were revealed using phycoerythrine-conjugated secondary antibodies. Stained cells were analyzed using flow cytometry excluding the none transfected GFP-negative cells. We then plotted the percentage of internalization as the ratio between the CD25-associated fluorescence that disappeared during the $30 \mathrm{~min}$ uptake at $37^{\circ} \mathrm{C}$ and the CD25-associated fluorescence at time $0 . C D 25$ is the reference protein without any viral cytoplasmic tail (negative control) and CD25-TFR is the CD25 reference protein in the cytoplasmic tail of which the well described YTRF endocytosis motif of the transferrin receptor has been inserted (positive control). mation capable of driving their retrograde transport to the TGN.

Mutation of the dileucine motif in position 3 did not drastically affect the capacity of the chimeras to be targeted to the TGN following internalization (Figure 7B). By contrast, chimeras mutated in the tyrosine-based motif in position 23 appeared localized in dispersed dots throughout the cytoplasm after their internalization. No colocalization was then apparent with MPR46 (Figure 7C).

Altogether, these data indicate that the TGN localization of the MLV and MPMV chimeras is the result of a complex trafficking involving retrieval of these proteins from endosomal compartments towards the TGN. This last step is driven by the tyrosine-based motif in position 23 that is conserved between both retroviruses.

\section{MLV cytoplasmic tail interacts with adaptor protein complexes (AP) I, 2 and 3}

To better understand the molecular basis of the intracellular sorting of the viral chimeras, we assessed the ability of the viral CT to physically interact with components of the adaptor protein complexes AP-1, AP-2 and AP-3 in a yeast two-hybrid assay. Because we have shown that both MLV and MPMV Env share the same trafficking, we decided to restrict our biochemical analysis to one virus. Thus, MLV $\mathrm{CT}$ was fused to the N-terminus of the LexA binding domain (BD), whereas the $\mu 1, \gamma$ and $\beta 1$ chains of AP1, the $\mu 2, \alpha$ and $\beta 2$ chains of AP2 and the $\mu 3, \delta$ and $\beta 3$ chains of AP3 were fused to the Gal4 activation domain (AD). MLV CT did not interact with $\gamma$ or $\beta 1$ subunits of AP1, $\alpha$ or $\beta 2$ subunits of AP2, or $\delta$ and $\beta 3$ subunits of AP3 in yeast twohybrid system (data not shown). By contrast, MLV CT bound to $\mu 1, \mu 2$ and $\mu 3$ medium chains as indicated by the expression of the HIS3 reporter gene, which allows cell growth in the absence of histidine (figure $8 \mathrm{~A}, 8 \mathrm{~B}$ and $8 \mathrm{C}$ ). However, interaction with $\mu 2$ only appeared after 72 hours growth (figure $8 \mathrm{~B}$ ), whereas interaction with $\mu 1$ and $\mu 3$ were present after 30 hours growth (figure $8 \mathrm{~A}$ and $8 \mathrm{C}$ ), indicating that binding to $\mu 2$ was weaker than the other interactions.

Mutation of the tyrosine in position 23 completely abolished interaction of the MLV CT with all three $\mu 1, \mu 2$ and $\mu 3$ chains of AP complexes (figure $8 \mathrm{~A}, 8 \mathrm{~B}$ and $8 \mathrm{C}$ ). On the contrary, mutation of the leucine in position 3 did not affect interaction with any of the $\mu$ chains (figure $8 \mathrm{~A}, 8 \mathrm{~B}$ and $8 \mathrm{C}$ ). These results therefore indicate the tyrosine 23 is critical for binding of the MLV cytoplasmic tail to the isolated $\mu$ subunits, and further demonstrate the specificity of these interactions.

We then examined whether a GST fusion of the MLV CT was able to recruit the whole preformed AP complexes 
A.

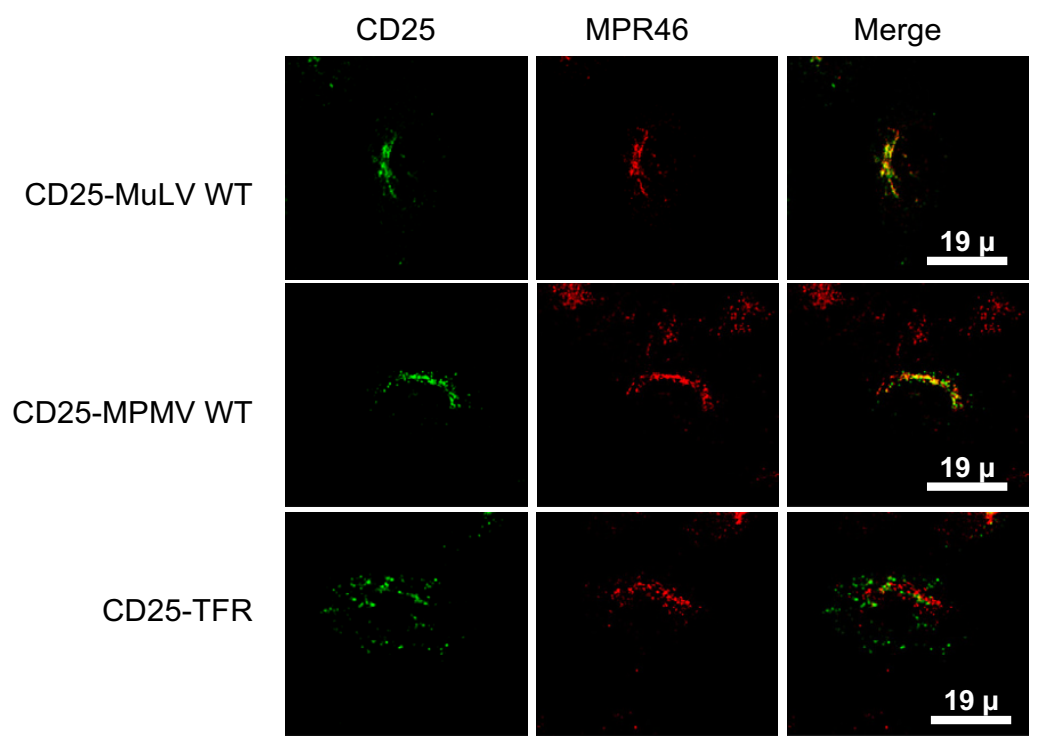

B.

CD25-MuLV L3S
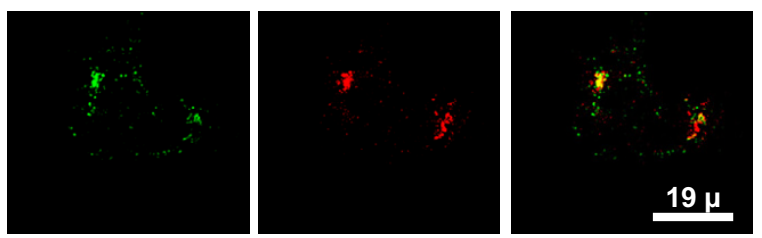

CD25-MPMV L3S
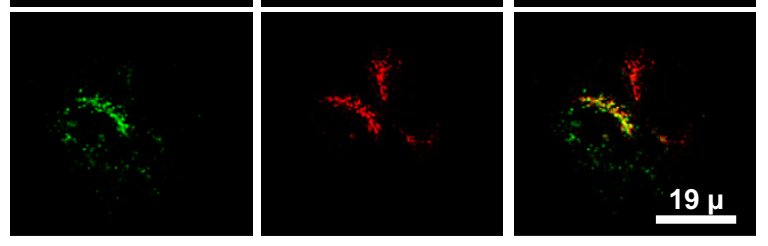

C.

CD25-MuLV Y23S
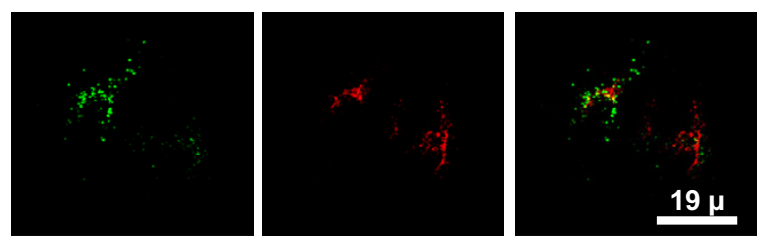

CD25-MPMV Y23S
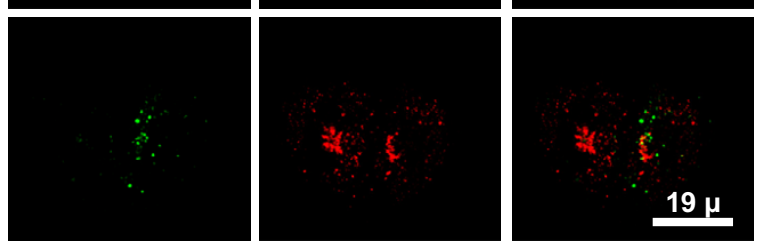

\section{Figure 7}

The tyrosine-based motif in position 23 allows the chimera to follow a retrograde route from endosomes to TGN. HeLa cells were transfected with A wild type, B L3S mutated or C Y23S mutated chimeras. Forty-eight hours after transfection, cells were treated with cycloheximide for $2 \mathrm{~h}$. Chimeras present on cell surface were stained with the anti-CD25 antibody at $4^{\circ} \mathrm{C}$ for I hour and cells were then shifted at $37^{\circ} \mathrm{C}$ for another hour. After fixation, internalized anti-CD25 was revealed using FITC-conjugated secondary antibodies, and MPR46 was revealed as in figure I. 


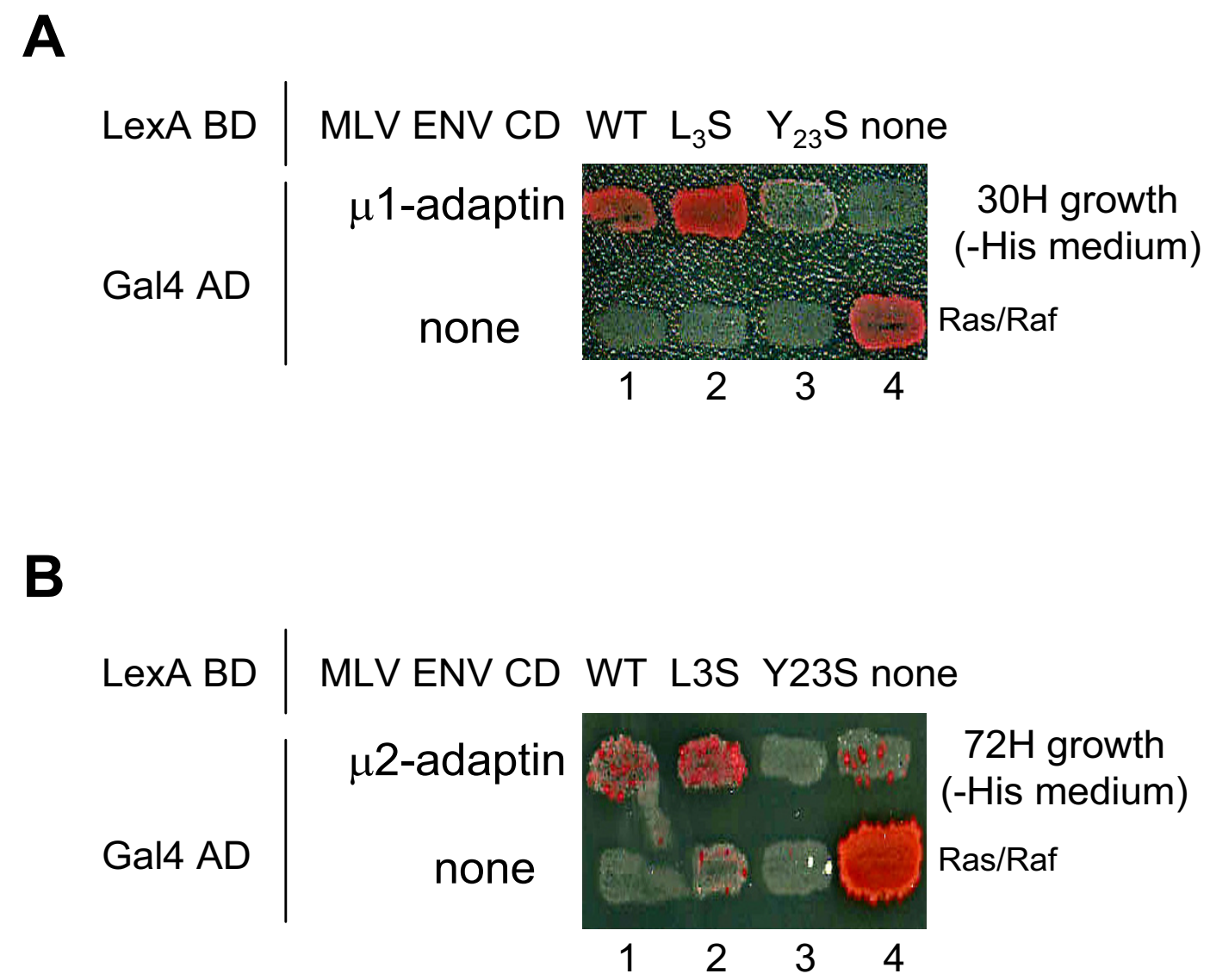

C

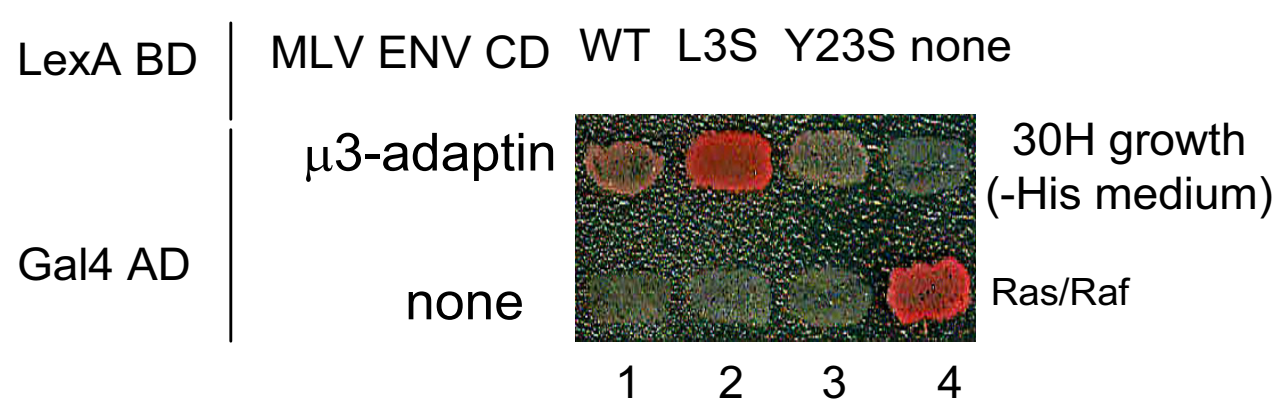

Figure 8

Interaction of the MLV TM-CD with $\mu I, \mu 2$ and $\mu 3$ subunits in the yeast two-hybrid system. The yeast reporter strain L40 was co-transformed with plasmids encoding Gal4 AD- $\mu$ I, $\mu 2$ and $\mu 3$-adaptin (A, B and C, respectively), and plasmids encoding lexA BD fused to either the wild type (WT) or mutated (L3S, Y23S) cytoplasmic tail of MLV. Cotransformants were analyzed for histidine auxotrophy. They were patched on medium with histidine and then replica-plated on medium without histidine (- His medium). Growth in the absence of histidine indicates interaction between hybrid proteins. The positive control was the interaction between Ras and Raf proteins which bind to each other efficiently (lane 4, lower patch in panels A, $B, C)$. Binding specificity was verified by the absence of interaction between the retroviral cytoplasmic tails (WT, L3S and Y23S) and the Gal4AD alone (none). 
Table I: Summary of the roles of the motifs in MLV and MPMV Env CT in subcellular Env trafficking.

\begin{tabular}{|c|c|c|}
\hline MOTIF (MLV/MPMV) & ROLE IN TRAFFICKING & EFFECT OF MUTATION \\
\hline${ }^{23} Y_{H Q L}{ }^{26 / 23} Y H R L 26$ & Endocytosis & Increase plasma membrane localization \\
\hline 23YHQL $26 / 23 Y H R{ }^{26}$ & TGN retrieval & Delocalization in unidentified late-endocytic compartments \\
\hline${ }^{3} \mathrm{LV}^{4} /{ }^{3} \mathrm{LM}^{4}$ & Sorting from TGN & Delocalization in the endosomal pathway \\
\hline
\end{tabular}

from HeLa cells lysates. AP1, AP2 and AP3 complexes were revealed using antibodies to $\gamma$-adaptin, $\alpha$-adaptin and $\delta$-adaptin, respectively. Immunoblot analysis of the cellular proteins retained on GST-MLV beads indicated that AP1, AP2 and AP3 bound specifically to the viral cytoplasmic tail (figure 9A, 9B and 9C). Mutation of either the tyrosine 23 or the leucine 3 affected the binding of the resulting GST-MLV to the AP2 complex (figure 9B). Interestingly, mutating the leucine 3 strongly affected the binding to AP1 and AP3, whereas mutation of the tyrosine 23 had no effect (figure 9A and 9C).

We thus showed that MLV cytoplasmic tail interacts not only with the $\mu$ chains of clathrin adaptors type 1, 2 and 3 , but also associates with the AP complexes from cell lysates. Optimal interaction with AP2 requires both the dileucine- and the tyrosine-based motif in position 3 and 23 , respectively. On the other hand, interactions with AP1 and AP3 complexes depend only on the dileucine-based motif.

\section{Discussion}

In this study, we analyzed the intracellular trafficking of two oncoretroviral envelope proteins, these of MLV and MPMV retroviruses. Their peculiar trafficking resulted in the dynamic intracellular retention of the proteins in the TGN and was driven by the association of two conventional sorting signals conserved in position between the two envelope glycoprotein cytoplasmic tails: a membrane proximal dileucine-based motif $\left({ }^{3} \mathrm{LV}^{4} /{ }^{3} \mathrm{LM}^{4}\right.$ in $\mathrm{MLV}$ and MPMV sequences respectively) and a more distal tyrosinebased motif (23YHQL ${ }^{26} /{ }^{23} \mathrm{YHRL}^{26}$ ).

To evaluate the roles of the CT of MLV and MPMV envelope glycoproteins in regulating their trafficking, we used an approach based on the study of chimeras between the whole CD25 chain and the cytoplasmic tail of retroviral Env proteins. Study of CD25 chimeras is a broadly used approach to assess the role of the cytoplasmic tail of different cellular proteins in their trafficking [17-19]. We and others have used this approach to study the trafficking of different retroviral glycoproteins $[5,9,11,12]$. Using CD25 chimeras permitted us to conduct a comparative work and to avoid complications inherent to the use of native viral envelope glycoproteins such, as shedding of the SU subunit in the extracellular medium or cytopathogenic effects due to envelope induced cell-cell fusion. Importantly, we previously demonstrated that native viral glycoproteins displayed the same intracellular trafficking as their chimeras counterparts, thus legitimazing the use of this approach $[8,9,12]$.

We previously showed that CD25-MLV and CD25-MPMV chimera appeared retained in an intracellular tubularshaped perinuclear compartment [12]. We now show that this compartment is distinct from the early/recycling endosomes or lysosomes and is enriched with the MPR46 protein. MPR46 mediates the transport of lysosomal enzymes from the TGN to endosomal prelysosomal compartments. After delivery of its cargo in acidic compartments, MPR returns to the TGN [20]. At steady state, MPR46 is found in the TGN, although a fraction may be found in endosomes $[21,22]$. We therefore concluded that the majority of CD25-MLV and CD25-MPMV localized in the TGN.

The TGN localization of both chimeras was dependent on the integrity of two sorting motifs. Mutating the dileucinebased motif in position 3 resulted in a partial delocalization of the chimeras throughout the endosomal pathway, without affecting their capacity to follow the retrograde route to the TGN when internalized from the plasma membrane. By contrast, mutation of the tyrosine-based motif in position 23 totally abolished the TGN localization of the chimeras, as well as their ability to be retrieved from endosomes to the TGN. The Y23S mutated chimeras then appeared accumulated in an endosomal compartment. Because this compartment was stained after internalization of dextran followed by a chase and was distinct from the early/recycling endosomes and lysosomes, we conclude that it must represent some late endosomal compartment. This compartment, however, did not contain CD63, a typical marker for late endosmes/multivesicular bodies (data not shown) and its exact nature remains to be identified. Regardless, these data allow us to propose the following model for the complex intracellular trafficking of the CD25-MLV and CD25-MPMV chimeras:

While exiting the biosynthetic pathway at the TGN level, the chimeric proteins are sorted to a specific late endosomal compartment. This sorting step involves the dileucine-based motif and mutation of this motif results in misrouting the proteins throughout the endosomal pathway (Table 1). Alternatively, Env proteins can also reach 
A

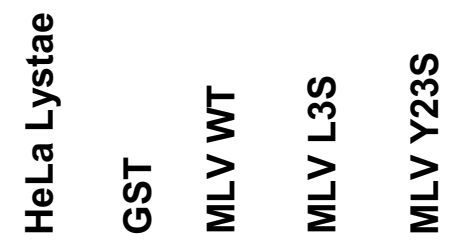

B

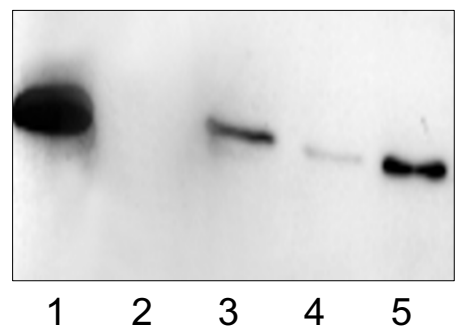

\section{AP-1 \\ $(\gamma$-adaptin)}
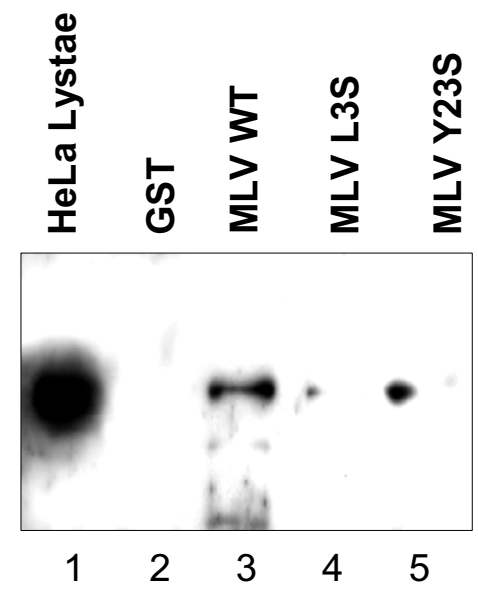

\section{AP-2 \\ ( $\alpha$-adaptin)}

C
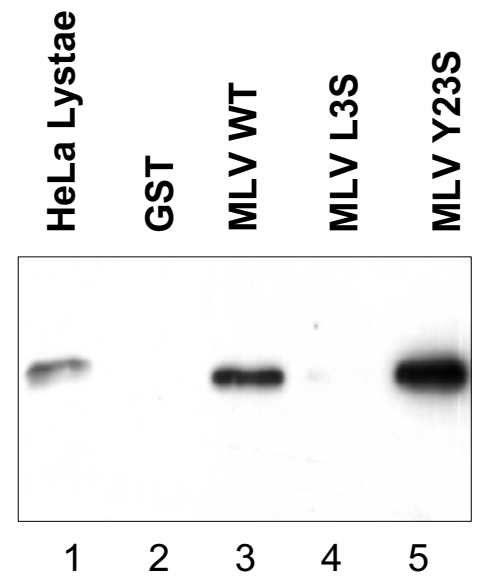

AP-3

( $\delta$-adaptin)

Figure 9

Interaction between GST fusions of WT or mutated MLV cytoplasmic tail and AP-I, AP-2 and AP-3 com-

plexes. Identical quantities of GST (5 $\mathrm{g}$ ) (lanes 2, panels A-C), GST-MLV (lanes 3), GST-MLV-L3S (lanes 4,), GST-MLV-Y23S

(lanes 5) were incubated with HeLa cell lysates $\left(2.5 \times 10^{6}\right.$ cells). The binding of AP-I, AP-2 and AP-3 complexes to GST fusion proteins was revealed by Western blotting with anti- $\gamma$ adaptin $\mathrm{mAb}$ (panel $\mathbf{A}$ ), anti- $\alpha$ adaptin $\mathrm{mAb}$ (panel $\mathbf{B}$ ) and anti- $\delta$ adaptin mAb (panel C). The positions of the $\alpha$-adaptin $(M r \sim 100,000), \gamma$-adaptin $(M r \sim 104,000)$ and $\delta$-adaptin $(M r \sim 90,000)$ are indicated in the crude cell lysate from $10^{6}$ cells (lanes I). 
the late endosomal compartment after internalization from the plasma membrane. Once the chimeras reach the specific late endosomal compartment, their tyrosinebased motif in position 23 mediates their trafficking in a retrograde pathway up to the TGN. If the tyrosine-based motif is mutated, the chimeras accumulate in the late endosomal compartment (Table 1). On the contrary, the wild type chimeras continuously cycle between endosomes and the TGN. The fact that chimeric proteins appear accumulated in the TGN at steady state indicates that the limiting step of their trafficking is the sorting event at the TGN level. Lastly, chimeras that make it to the plasma membrane are being internalized and delivered back to the TGN, both steps implicating the tyrosinebased motif in position 23 (Table 1).

This model is reinforced by the biochemical study we conducted on the MLV tail. Indeed, GST pull down assays confirmed that the dileucine-based motif is important for interaction with AP1 and AP3 complexes that are implicated in sorting cargos at the TGN level (review in [23]), whereas the tyrosine-based motif is somehow dispensable for this process. On the contrary both dileucine- and tyrosine-based motifs are important for the optimal recruitment of the AP2 complexes that function in endocytosis [24]. However, the direct interaction we detected in yeast two-hybrid between MLV cytoplasmic tail and the $\mu 2$ chain of AP2 appeared weaker than interaction with $\mu 1$ or $\mu 3$. This is consistent with our findings that trafficking of CD25-MLV chimeras is mainly restricted between intracellular compartments and that the MLV tyrosine-based signal is not optimized for the binding to the AP2 complexes. These findings nevertheless indicate that when the chimeras eventually reach the plasma membrane, they can be cleared from cell surface following endocytosis.

Our biochemical data does not elucidate how the tyrosine-based motif in position 23 mediates the retrograde route of the CD25-MLV and CD25-MPMV chimeras from late endosomal compartment to the TGN. One retrograde transport pathway to TGN involves the AP1 clathrin adaptor $[25,26]$. In our yeast two-hybrid experiments, we elucidated an interaction between the $\mu 1$ chain of AP1 and MLV cytoplasmic tail. This interaction depended on the integrity of the tyrosine-based motif in position 23. In our GST pull down assay, however, the tyrosine 23 appears dispensable for the interaction with AP1 complexes. These contrasting results might indicate that, although the tyrosine-based motif is capable to bind the isolated $\mu$ chains of AP complexes in the yeast two-hybrid system, it might not be able to mediate the interaction with the whole AP1 complex. Alternatively, it is also possible that the interaction of the MLV and MPMV Env CTs with AP1 complexes during the retrograde transport might involve additional informations, like other determinants located in the Env
CTs. Another possibility is that the tyrosine-based motif functions in the retrograde transport by recruiting other adaptors than AP1. Indeed, different retrograde pathways have been described for the furin and MPRs proteins. Retrograde transport of the furin protein involves an interaction of an acid cluster of amino-acids with the adaptor protein PACS1 $[27,28]$ while retrograde transport of the MPRs requires either interaction of a motif constituted by two successive aromatic amino-acids (MPR46) or by prolines (MPR300) with the TIP47 adaptor [29,30]. None of these kinds of motifs can be found in either MLV or MPMV cytoplasmic tails suggesting that these viral proteins follow a different retrograde route using an unknown mechanism or use new motifs to interact with these adaptors. Formal demonstration of this would however require more biochemical analysis to directly test the interaction of MLV and MPMV cytoplasmic tails with PACS1 and TIP47.

Interestingly, it has been demonstrated that Epsin R can recruit clathrin either directly or through AP1 [31-34]. This recruitment is important for an AP1-independent retrograde pathway followed by TGN38 and MPR300 [35]. Because it has proposed that Espin R may function as a cargo adaptor [36], further studies should also assess the putative relationship between Epsin $\mathrm{R}$ and the retrograde transport mediated by MLV and MPMV cytoplasmic tails.

The dileucine 3- and tyrosine 23-based motifs in MLV and MPMV cytoplasmic tails are very similar to each other in term of sequence and are conserved in position (Fig 2). Nevertheless, MLV and MPMV infect different hosts, belong to two different retrovirus genuses and appear highly divergent on a phylogenetic tree. We can thus postulate that these two motifs and the intracellular trafficking they regulate must be essential for efficient replication and propagation of these viruses. We and others have shown that, regardless of whether they are from the oncoretrovirus or the lentivirus family, all retrovirus envelope glycoproteins follow complex intracellular routes $[5,8-10,12]$. It has been proposed that these different intracellular trafficking routes were part of mechanisms allowing the virus to escape the host immune response by limiting the amount of antigenic envelope glycoproteins at the cell surface of infected cells. Thus, a simian immunodeficiency virus bearing a mutation in the tyrosine-based endocytosis signal of its envelope glycoproteins is attenuated in vivo [37], although envelope incorporation into virions and virions infectivity are both normal in vitro [38]. Moreover, mutation of the same tyrosine-based endocytosis signal in HIV enhances the immunogenicity of a vaccine preparation, in correlation with enhanced surface expression of the protein [39]. However, the fact that the intracellular trafficking pathways we describe are much more complex than just endocytosis suggests that 
they play other roles than just limiting the amount of envelope glycoproteins present at the cell surface.

In the last few years, it was demonstrated that the Gag polyproteins of retroviruses hijack various host proteins and use them for assembly and budding of particles (reviewed in $[2,3]$ ). All the cellular factors described so far to participate in this phenomenon are proteins that function in different stages of the endosomal trafficking: Nedd4 [40-42], Tsg101 and other ESCRT-1 components [40,42-44], AIP1/ALIX [45], AP2 [46] and AP3 [47]. Growing number of evidence indicate that Gag proteins are transported along the endosomal pathway prior to assembly and budding [42,47-56]. Thus, targeting envelope glycoproteins in the endosomal pathway might help Env encountering Gag and being subsequently incorporated in the nascent virion. That Env glycoproteins constantly traffic in a cycling pathway between TGN and endosomes as we described here would furthermore allow them to wait inside the cell until they encounter the Gag proteins in endosomes, and are subsequently rerouted to be incorporated into budding particles.

Supporting this hypothesis, it has been shown that HIV-1 envelope glycoproteins also follow an anterograde/retrograde pathway and that this trafficking step is required for optimal incorporation of Env into virions and subsequent infectivity of the virus [9]. We also found that bovine leukemia virus envelope cytoplasmic tail possesses dileucine- and tyrosine-based motifs that drive its trafficking in a TGN-endosome cycling pathway (Blot et al, unpublished data). Finally, the tyrosine-based motifs in position 23 in the cytoplasmic tail of MLV and MPMV envelope glycoproteins, which we found are necessary to maintain the protein in the endosomes to the TGN retrograde route, are also necessary for efficient incorporation of Env into virus particles $[57,58]$.

Finally, regulated Env intracellular trafficking might also be important for intracellular Gag sorting and subsequent efficient virus release. Indeed, it has been shown that Env can influence Gag intracellular localization for both MLV [53] and MPMV [48]. MLV can be released in a polarized manner and this process depends on the integrity of the tyrosine-based motif in Env CT [10,59]. MPMV follows the Type-D assembly pathway in which Gag pre-assembled in the cytoplasm. It has been recently shown that preassembled MPMV Gag are localized on pericentriolar microdomains and Env is required to promote Gag transport out of this perinuclear site [48]. It will thus be of great interests to test the importance of Env tyrosine-based and dileucine-based motifs in this process. It was long thought that the whole process of retrovirus assembly occurs at the plasma membrane of infected cells. Accumulating evidence now complicates this simple scheme and suggests that retroviruses developed strategies ensuring the specific sorting of their structural proteins into intracellular compartments. These complex routes may be viewed as a funnel, concentrating the different structural components of the viruses from their synthesis sites dispersed throughout the cell towards a unique platform of assembly. The discovery of such mechanisms may provide new targets to develop antiretroviral drugs. Understanding the precise mechanisms that underlie the transport of viral proteins inside the cells and their interactions with host cell factors during assembly and budding appears then as an important future challenge for retrovirology.

\section{Conclusion}

We found here that two unrelated retroviruses, MLV and MPMV, share the capacity to acutely regulate the trafficking of their envelope glycoprotein inside the cells. Env intracellular trafficking involves a cycling loop between the TGN and endosomes. Due to the presence of dileucine- and tyrosine-based motifs conserved in sequence and position in MLV and MPMV Env cytoplasmic tails, Env interact with clathrin adaptors. Thus, both structural Gag and Env proteins hijack the host cell machinery involved in trafficking in the endosomal pathway, which could be used as an assembly platform.

\section{Methods \\ Plasmids and cells}

The CD25, CD25-TFR, CD25-MLV and CD25-MPMV chimeras were previously described [12]. Mutagenesis was performed by PCR using the Quickchange ${ }^{\mathrm{TM}}$ Site-directed mutagenesis kit (Stratagene) according to the manufacturer's instructions and plasmids were then sequenced by automatic sequencing (sequencing core facility, Institut Cochin, Paris, France). The amino acid sequences of the resulting chimeric proteins are shown in Fig. $2 \mathrm{~B}$.

HeLa cells were grown in Dulbecco's Modified Eagle Medium (DMEM) supplemented with $10 \%$ fetal calf serum (FCS), gentamycine and $2 \mathrm{mM}$ L-glutamine. Transient transfections were performed using the calcium phosphate procedure. For indirect immunofluorescence assays, $2.10^{4}$ cells plated per well of 24-well plates were transfected with $300 \mathrm{ng}$ (steady state analysis) or $500 \mathrm{ng}$ (antibody uptake assays) plasmid. The total quantity of DNA was normalized to $1 \mu \mathrm{g}$ by adding empty vector (pcDNA3). For flow cytometry analysis, 7.105 HeLa cells plated in $100 \mathrm{~mm}$ dishes were co-transfected with $4 \mu \mathrm{g}$ of chimera encoding plasmid and $2 \mu \mathrm{g}$ of pEGFP1 vector (Clontech), which allowed the detection of transfected cells by the expression of green-fluorescent protein (GFP). The total amount of DNA was normalized to $10 \mu \mathrm{g}$ by adding empty vector. 


\section{Antibodies and Fluorescent Reagents}

The 7G7B6 and 2A3A1H monoclonal antibodies (MAb) directed to CD25 were obtained from ascites fluids (gift of A. Dautry-Varsat, Institut Pasteur, Paris, France). The antiMPR46 is an affinity purified rabbit serum provided by $\mathrm{S}$. Höning (University of Göttingen, Germany)[22]. The anti-Lamp $1 \mathrm{MAb}$ coupled to FITC was purchased from Pharmingen (San Diego CA, USA). The transferrin receptor was revealed using cyanine 3-conjugated human transferrin (gift of A. Dautry-Varsat, Institut Pasteur, Paris, France). The FITC-conjugated dextran was purchased from Molecular Probes.

\section{Intracellular staining and confocal microscopy}

Forty-eight hours after transfection, cells grown on glass coverslips (Polylabo, France) were treated with cycloheximide $(500 \mu \mathrm{M})$ (Sigma) for $3 \mathrm{~h}$ before fixation for $15 \mathrm{~min}$ in PBS-4\% paraformaldehyde at room temperature, and quenching for $15 \mathrm{~min}$ in PBS-0.1 M glycine. Cells were then permeabilized for $40 \mathrm{~min}$ with PBS containing $0.05 \%$ saponin and $0.2 \%$ bovine serum albumin (BSA) (permeabilizing buffer). CD25 chimeras and human MPR46 marker were co-stained using the anti-CD25 7G7B6 MAb (ascites fluid, 1/500 dilution in permeabilizing buffer) and anti-MPR46 affinity purified rabbit antiserum (1/500) for $1 \mathrm{~h}$. After washes, the staining was revealed using FITC-coupled goat anti-mouse Ig and cyanine 3-coupled goat anti-rabbit Ig (Jackson Immunoresearch Laboratories, Inc., 1/300). Cells were mounted in mowiol (Calbiochem, California, USA) and examined under a confocal microscope (MRC-1024, Bio Rad). All images presented are single slices from median sections of cells.

For colocalization with Lamp-1, cells were saturated using non immune murine sera $(1 / 100$, in permeabilizing buffer) following the CD25 staining. Lamp-1 was then revealed by a $1 \mathrm{~h}$ incubation with $1 / 50$ dilution of FITCconjugated anti-lamp-1 MAb (Pharmingen, CA, USA) in permeabilizing buffer complemented with a 1/50 dilution of non-immune murine sera. Late endosomal compartments were revealed by incubating living transfected cells with FITC-conjugated dextran $(2 \mathrm{mg} / \mathrm{ml}$ in complete medium) for $30 \mathrm{~min}$ at $37^{\circ} \mathrm{C}$ followed by a $30 \mathrm{~min}$ chase using complete medium, whereas early/recycling compartments were stained after a $30 \mathrm{~min}$ internalization of cyanin3-conjugated transferrin (100 $\mathrm{nM}$ in serum free medium). Cells were then fixed and CD25 chimeras were revealed as described above.

\section{Flow cytometry}

Cells were collected 48 hours after transfection by incubation with PBS containing $5 \mathrm{mM}$ EDTA for $10 \mathrm{~min}$, pelleted and suspended in ice-cold PBS. They were then incubated for $1 \mathrm{~h}$ with the anti-CD25 2A3A1H MAb (ascites fluid, 1/
2000 ) in $100 \mu \mathrm{l}$ of PBS at $4^{\circ} \mathrm{C}$, washed $2 \times$ with chilled PBS, and stained with phycoerythrine conjugated goat anti-mouse Ig (Caltag, California, USA) for $1 \mathrm{~h}$ at $4{ }^{\circ} \mathrm{C}$. The cells were washed and fixed in PBS containing $2 \%$ formaldehyde (FAD), and analyzed by flow cytometry after gating on the GFP-positive population.

\section{Internalization assay}

Transfected cells were collected as described above, incubated with the anti-CD25 2A3A1H MAb (ascites fluid, 1/ 2000) for $1 \mathrm{~h}$ on ice, and washed in chilled PBS. Cells were then either kept at $4^{\circ} \mathrm{C}(\mathrm{t}=0)$ or shifted to $37^{\circ} \mathrm{C}$ for $30 \mathrm{~min}$, rapidly cooled to $4^{\circ} \mathrm{C}$ and washed once $(\mathrm{t}=30)$. MAbs bound to the cell surface were then revealed by incubation with phycoerythrine-coupled goat anti-mouse Ig for $1 \mathrm{~h}$ at $4^{\circ} \mathrm{C}$. After two washes with chilled PBS, cells were fixed in PBS-2\% FAD and analyzed by flow cytometry. GFP-negative cells were excluded from the analysis. The internalization of chimeras was estimated as follow: $\left[\left(\mathrm{mfi}_{\mathrm{t}=0}\right)-\left(\mathrm{mfi}_{\mathrm{t}=30}\right)\right] /\left[\left(\mathrm{mfi}_{\mathrm{t}=0}\right)-\left(\mathrm{mfi}_{\text {neg }}\right)\right] \times 100$, where $\mathrm{mfi}_{\mathrm{t}}$ is the mean fluorescence intensity of cells harvested after incubation for either $0 \mathrm{~min}$ or $30 \mathrm{~min}$ at $37^{\circ} \mathrm{C}$ and $\mathrm{mfi}_{\text {neg }}$ is the background staining without primary antibody.

\section{Analysis of the retrograde transport}

For analysis of the endosome-to-TGN retrograde transport, HeLa cells were transiently transfected with $500 \mathrm{ng}$ chimera expressing vectors and analyzed $48 \mathrm{~h}$ after transfection. Cells were treated $2 \mathrm{~h}$ with cycloheximide (500 $\mu \mathrm{M})$ and incubated with the 7G7B6 MAb $(1 / 500$ in chilled PBS) for $1 \mathrm{~h}$ on ice. Then cells were shifted at $37^{\circ} \mathrm{C}$ in complete medium containing cycloheximide for $1 \mathrm{~h}$, fixed and permeabilized as described above. The TGN compartment was revealed by anti-MPR46 affinity purified rabbit serum (1/500), followed by a co-incubation of FITC conjugate anti-mouse Ig (1/300) and cyanine 3 conjugate anti-rabbit Ig (1/300).

\section{Yeast two-hybrid assays}

DNA fragment encoding MLV cytoplasmic tail (amino acid residues 1 to 33; Figure 2A) was generated by PCR and cloned in frame with the LexA binding domain (BD) into the pFBL2-3 vector, a gift of J. Camonis (Institut Curie, Paris), (pFBL-MLV). Point mutations of the tyrosine 23 and leucine 3 residues were introduced by PCRbased site-directed mutagenesis using the appropriate primers to generate the following constructs: pFBL-MLVL3S, pFBL-MLV-Y23S. Mutations were verified by DNA sequencing. Plasmids for expressing the $\mu 1, \gamma$ and $\beta 1$ chains of AP1 complex, the $\mu 2, \alpha$ and $\beta 2$ chains of AP2 and the $\mu 3, \delta$ and $\beta 3$ chains of AP3 fused to the Gal4 activation domain $(\mathrm{AD})$ in the $\mathrm{PACTII}$ vector were kindly provided by J. S. Bonifacino (NIH, Bethesda, MD) [7] and M. Robinson (University of Cambridge, Cambridge) [60]. The yeast reporter strain L40 containing the HIS3 LexA 
were co-transformed with the indicated LexA BD and Gal4 $\mathrm{AD}$ expression vectors, and plated on selective medium lacking tryptophan and leucine. Double transformants were patched on the same medium and then analyzed for histidine auxotrophy by replica-plating on selective medium lacking tryptophan, leucine and histidine [5].

\section{GST-pull down assays}

DNA fragment containing the cytoplasmic tail of MLV was obtained by PCR and cloned in-frame with GST (glutathione S-transferase) into the $\mathrm{pGex}$-2TH vector to generate pGex-MLV. Point mutations of the essential L3 and Y23 residues were introduced by PCR and the following constructs were obtained: pGex-MLV-L3S, pGex-MLV-Y23S.

Bacterially-expressed GST chimeric proteins and unfused GST (control) were purified and immobilized on GSHagarose beads as previously described [5]. Coomassie blue staining of polyacrylamide gel was used to control that the beads were coated with the same amount of GST recombinant proteins. GST-fusion proteins $(5 \mu \mathrm{g})$ immobilized on GSH-agarose beads were incubated $1 \mathrm{~h}$ at $4{ }^{\circ} \mathrm{C}$ in PBS containing $2 \mathrm{mg} / \mathrm{ml}$ BSA and $0.05 \%$ Tween. HeLa cells were lysed in lysis buffer $(50 \mathrm{mM}$ Tris $\mathrm{pH} 8,150 \mathrm{mM}$ $\mathrm{NaCl}, 5 \mathrm{mM}$ EDTA, 1\% Triton X-100). HeLa cell lysates corresponding to $2.5 .10^{7}$ cells were incubated overnight at $4^{\circ} \mathrm{C}$ with $5 \mu \mathrm{g}$ GST fusion proteins or GST control immobilized on GSH-agarose beads. The beads were then washed five times with lysis buffer. Bound proteins were eluted, separated by SDS-PAGE and revealed by Western blotting with anti- $\gamma$ adaptin $\mathrm{mAb}$ (Transduction laboratories), anti- $\alpha$ adaptin $m A b$ (clone 100/2, Sigma) and anti$\delta$ adaptin $\mathrm{mAb}$ (Transduction laboratories).

\section{Abbreviations}

MLV: Moloney murine leukemia virus; MPMV: MasonPfizer monkey virus; HIV: human immunodeficiency virus; Env: envelope glycoprotein; CT: cytoplasmic tail; AP: adaptor protein; TGN: Trans Golgi network

\section{Competing interests}

The author(s) declare that they have no competing interests.

\section{Authors' contributions}

VB and MPG designed and conducted the study, performed the experiments and wrote the manuscript. $\mathrm{MB}$ helped setting up the assays. CBT contributed to draft the manuscript and conducted the yeast two-hybrid and GST pull down studies. SLV performed the yeast two-hybrid and GST pull down experiments, and contributed to draft the manuscript. CP contributed to the data interpretation and to draft the manuscript.

\section{Acknowledgements}

Thanks are due to J. Bonifacino and to J. Camonis for the kind gift of reagents and to $\mathrm{L}$. Tortorella for her critical reading of the manuscript. SLV received a fellowship from MENRT (Université Paris 7 - Denis Diderot). This work was supported by grants from the ANRS, the FRM and SIDACTION.

\section{References}

I. Hunter E, Swanstrom R: Retrovirus envelope glycoproteins. Curr Top Microbiol Immunol 1990, 157:187-253.

2. Demirov DG, Freed EO: Retrovirus budding. Virus Res 2004, 106:87-102.

3. Rowell JF, Stanhope PE, Siliciano RF: Endocytosis of endogenously synthesized HIV-I envelope protein. Mechanism and role in processing for association with class II MHC. J Immunol I995, 155:473-488.

4. Berlioz-Torrent C, Shacklett BL, Erdtmann L, Delamarre L, Bouchaert I, Sonigo P, Dokhelar MC, Benarous R: Interactions of the cytoplasmic domains of human and simian retroviral transmembrane proteins with components of the clathrin adaptor complexes modulate intracellular and cell surface expression of envelope glycoproteins. J Virol 1999, 73:1350-I36I.

5. Boge M, Wyss S, Bonifacino JS, Thali M: A membrane-proximal tyrosine-based signal mediates internalization of the HIV-I envelope glycoprotein via interaction with the AP-2 clathrin adaptor. J Biol Chem 1998, 273:15773-15778.

6. Ohno H, Aguilar RC, Fournier MC, Hennecke S, Cosson P, Bonifacino JS: Interaction of endocytic signals from the HIV-I envelope glycoprotein complex with members of the adaptor medium chain family. Virology 1997, 238:305-3I5.

7. Wyss S, Berlioz-Torrent C, Boge M, Blot G, Honing S, Benarous R, Thali $M$ : The highly conserved $C$-terminal dileucine motif in the cytosolic domain of the human immunodeficiency virus type I envelope glycoprotein is critical for its association with the AP-I clathrin adaptor [correction of adapter]. J Virol 200I, 75:2982-2992.

8. Blot G, Janvier K, Le Panse S, Benarous R, Berlioz-Torrent C: Targeting of the human immunodeficiency virus type I envelope to the trans-Golgi network through binding to TIP47 is required for env incorporation into virions and infectivity. J Virol 2003, 77:6931-6945.

9. Lodge R, Delamarre L, Lalonde JP, Alvarado J, Sanders DA, Dokhelar MC, Cohen EA, Lemay G: Two distinct oncornaviruses harbor an intracytoplasmic tyrosine-based basolateral targeting signal in their viral envelope glycoprotein. J Virol 1997, 71:5696-5702.

10. Novakovic S, Sawai ET, Radke K: Dileucine and YXXL motifs in the cytoplasmic tail of the bovine leukemia virus transmembrane envelope protein affect protein expression on the cell surface. J Virol 2004, 78:830I-83II.

II. Grange MP, Blot V, Delamarre L, Bouchaert I, Rocca A, Dautry-Varsat A, Dokhelar MC: Identification of two intracellular mechanisms leading to reduced expression of oncoretrovirus envelope glycoproteins at the cell surface. J Virol 2000, 74: I 1734-1 I743.

12. Goud B, Zahraoui A, Tavitian A, Saraste J: Small GTP-binding protein associated with Golgi cisternae. Nature 1990, 345:553-556.

13. Antony C, Cibert C, Geraud G, Santa Maria A, Maro B, Mayau V, Goud B: The small GTP-binding protein rab6p is distributed from medial Golgi to the trans-Golgi network as determined by a confocal microscopic approach. J Cell Sci 1992, 103 ( Pt 3):785-796.

14. Dell'Angelica EC, Payne GS: Intracellular cycling of lysosomal enzyme receptors: cytoplasmic tails' tales. Cell 200I, 106:395-398.

15. Chen JW, Murphy TL, Willingham MC, Pastan I, August JT: Identification of two lysosomal membrane glycoproteins. J Cell Biol 1985, 101:85-95.

16. Mallet WG, Maxfield FR: Chimeric forms of furin and TGN38 are transported with the plasma membrane in the transGolgi network via distinct endosomal pathways. J Cell Biol 1999, I 46:345-359.

17. Aguilar RC, Boehm M, Gorshkova I, Crouch RJ, Tomita K, Saito T, Ohno H, Bonifacino JS: Signal-binding Specificity of the $\{\mathrm{mu}\} \mathbf{4}$ 
Subunit of the Adaptor Protein Complex, AP-4. J Biol Chem 2001 .

18. Subtil A, Delepierre M, Dautry-Varsat A: An alpha-helical signal in the cytosolic domain of the interleukin 2 receptor beta chain mediates sorting towards degradation after endocytosis. J Cell Biol 1997, 136:583-595.

19. Korner C, Braulke T: Inhibition of IGF II-induced redistribution of mannose 6-phosphate receptors by the phosphatidylinositol 3-kinase inhibitor, wortmannin. Mol Cell Endocrinol 1996, I I 8:20I-205.

20. Geuze HJ, Stoorvogel W, Strous GJ, Slot JW, Bleekemolen JE, Mellman I: Sorting of mannose 6-phosphate receptors and lysosomal membrane proteins in endocytic vesicles. J Cell Biol 1988, 107:249|-250|.

21. Klumperman J, Hille A, Veenendaal T, Oorschot V, Stoorvogel W, von Figura K, Geuze HJ: Differences in the endosomal distributions of the two mannose 6-phosphate receptors. J Cell Biol 1993, I 21:997-1010.

22. Bonifacino JS, Traub LM: Signals for Sorting of Transmembrane Proteins to Endosomes and Lysosomes. Annu Rev Biochem 2003.

23. Pearse BM, Smith CJ, Owen DJ: Clathrin coat construction in endocytosis. Curr Opin Struct Biol 2000, 10:220-228.

24. Meyer C, Zizioli D, Lausmann S, Eskelinen EL, Hamann J, Saftig P, von Figura K, Schu P: mu IA-adaptin-deficient mice: lethality, loss of AP-I binding and rerouting of mannose 6-phosphate receptors. Embo J 2000, 19:2193-2203.

25. Meyer C, Eskelinen EL, Guruprasad MR, von Figura K, Schu P: Mu IA deficiency induces a profound increase in MPR300/IGF-II receptor internalization rate. J Cell Sci 200 I, I I 4:4469-4476.

26. Crump CM, Xiang Y, Thomas L, Gu F, Austin C, Tooze SA, Thomas G: PACS-I binding to adaptors is required for acidic cluster motif-mediated protein traffic. Embo J 200I, 20:2 I9I-220I.

27. Wan L, Molloy SS, Thomas L, Liu G, Xiang Y, Rybak SL, Thomas G: PACS-I defines a novel gene family of cytosolic sorting proteins required for trans-Golgi network localization. Cell 1998, 94:205-216.

28. Carroll KS, Hanna J, Simon I, Krise J, Barbero P, Pfeffer SR: Role of Rab9 GTPase in facilitating receptor recruitment by TIP47. Science 200I, 292: I373-1376.

29. Diaz E, Pfeffer SR: TIP47: a cargo selection device for mannose 6-phosphate receptor trafficking. Cell 1998, 93:433-443.

30. Kalthoff C, Groos S, Kohl R, Mahrhold S, Ungewickell Ej: Clint: a novel clathrin-binding ENTH-domain protein at the Golgi. Mol Biol Cell 2002, 13:4060-4073.

31. Wasiak S, Legendre-Guillemin V, Puertollano R, Blondeau F, Girard M, de Heuvel E, Boismenu D, Bell AW, Bonifacino JS, McPherson PS: Enthoprotin: a novel clathrin-associated protein identified through subcellular proteomics. J Cell Biol 2002, 158:855-862.

32. Mills IG, Praefcke G], Vallis Y, Peter B], Olesen LE, Gallop JL, Butler PJ, Evans PR, McMahon HT: EpsinR: an API/clathrin interacting protein involved in vesicle trafficking. J Cell Biol 2003, 160:213-222.

33. Hirst J, Motley A, Harasaki K, Peak Chew SY, Robinson MS: EpsinR: an ENTH domain-containing protein that interacts with API. Mol Biol Cell 2003, 14:625-64I.

34. Saint-Pol A, Yelamos B, Amessou M, Mills IG, Dugast M, Tenza D, Schu P, Antony C, McMahon HT, Lamaze C, Johannes L: Clathrin adaptor epsin $R$ is required for retrograde sorting on early endosomal membranes. Dev Cell 2004, 6:525-538.

35. Chidambaram S, Mullers N, Wiederhold K, Haucke V, von Mollard GF: Specific interaction between SNAREs and epsin N-terminal homology (ENTH) domains of epsin-related proteins in trans-Golgi network to endosome transport. J Biol Chem 2004, 279:4175-4179.

36. Fultz PN, Vance PJ, Endres MJ, Tao B, Dvorin JD, Davis IC, Lifson JD, Montefiori DC, Marsh M, Malim MH, Hoxie JA: In vivo attenuation of simian immunodeficiency virus by disruption of a tyrosinedependent sorting signal in the envelope glycoprotein cytoplasmic tail. J Virol 200I, 75:278-29|.

37. Sauter MM, Pelchen-Matthews A, Bron R, Marsh M, LaBranche CC, Vance PJ, Romano J, Haggarty BS, Hart TK, Lee WM, Hoxie JA: An internalization signal in the simian immunodeficiency virus transmembrane protein cytoplasmic domain modulates expression of envelope glycoproteins on the cell surface. I Cell Biol 1996, I32:795-8II.
38. Bu Z, Ye L, Vzorov A, Taylor D, Compans RW, Yang C: Enhancement of immunogenicity of an HIV Env DNA vaccine by mutation of the Tyr-based endocytosis motif in the cytoplasmic domain. Virology 2004, 328:62-73.

39. Gottwein E, Bodem J, Muller B, Schmechel A, Zentgraf $H$, Krausslich HG: The Mason-Pfizer monkey virus PPPY and PSAP motifs both contribute to virus release. J Virol 2003, 77:9474-9485.

40. Kikonyogo A, Bouamr F, Vana ML, Xiang Y, Aiyar A, Carter C, Leis J: Proteins related to the Nedd 4 family of ubiquitin protein ligases interact with the $\mathbf{L}$ domain of Rous sarcoma virus and are required for gag budding from cells. Proc Natl Acad Sci U S A 2001, 98: III 199-11204.

4I. Blot V, Perugi F, Gay B, Prevost MC, Briant L, Tangy F, Abriel H, Staub $\mathrm{O}$, Dokhelar MC, Pique C: Nedd4.I-mediated ubiquitination and subsequent recruitment of Tsg I0 I ensure HTLV-I Gag trafficking towards the multivesicular body pathway prior to virus budding. I Cell Sci 2004, I I 7:2357-2367.

42. Garrus JE, von Schwedler UK, Pornillos OW, Morham SG, Zavitz KH, Wang HE, Wettstein DA, Stray KM, Cote M, Rich RL, Myszka DG, Sundquist WI: TsgIOI and the vacuolar protein sorting pathway are essential for HIV-I budding. Cell 200I, 107:55-65.

43. Martin-Serrano J, Zang T, Bieniasz PD: Role of ESCRT-I in retroviral budding. I Virol 2003, 77:4794-4804

44. Strack B, Calistri A, Craig S, Popova E, Gottlinger HG: AIP I/ALIX is a binding partner for HIV-I p6 and EIAV p9 functioning in virus budding. Cell 2003, I | 4:689-699.

45. Puffer BA, Watkins SC, Montelaro RC: Equine infectious anemia virus Gag polyprotein late domain specifically recruits cellular AP-2 adapter protein complexes during virion assembly. J Virol 1998, 72: 10218-10221.

46. Dong X, Li H, Derdowski A, Ding L, Burnett A, Chen X, Peters TR, Dermody TS, Woodruff E, Wang JJ, Spearman P: AP-3 directs the intracellular trafficking of HIV-I Gag and plays a key role in particle assembly. Cell 2005, I 20:663-674.

47. Sfakianos JN, Hunter E: M-PMV capsid transport is mediated by Env/Gag interactions at the pericentriolar recycling endosome. Traffic 2003, 4:67I-680.

48. Sfakianos JN, LaCasse RA, Hunter E: The M-PMV cytoplasmic targeting-retention signal directs nascent $\mathrm{Gag}$ polypeptides to a pericentriolar region of the cell. Traffic 2003, 4:660-670.

49. Bouamr F, Melillo JA, Wang MQ, Nagashima K, de Los Santos M, Rein A, Goff SP: PPPYVEPTAP motif is the late domain of human T-cell leukemia virus type I $\mathbf{G a g}$ and mediates its functional interaction with cellular proteins Nedd4 and Tsg 101 [corrected]. I Virol 2003, 77:11882-11895.

50. Sherer NM, Lehmann MJ, Jimenez-Soto LF, Ingmundson A, Horner SM, Cicchetti G, Allen PG, Pypaert M, Cunningham JM, Mothes W: Visualization of retroviral replication in living cells reveals budding into multivesicular bodies. Traffic 2003, 4:785-80 I.

51. Nydegger S, Foti M, Derdowski A, Spearman P, Thali M: HIV-I egress is gated through late endosomal membranes. Traffic 2003, 4:902-910.

52. Basyuk E, Galli T, Mougel M, Blanchard JM, Sitbon M, Bertrand E: Retroviral genomic RNAs are transported to the plasma membrane by endosomal vesicles. Dev Cell 2003, 5: I6I-I74.

53. Segura-Morales C, Pescia C, Chatellard-Causse C, Sadoul R, Bertrand $E$, Basyuk $E$ : Tsg $10 \mathrm{I}$ and Alix interact with murine leukemia virus $\mathbf{G a g}$ and cooperate with Nedd4 ubiquitin ligases during budding. J Biol Chem 2005, 280:27004-270I 2.

54. Sandrin V, Muriaux D, Darlix JL, Cosset FL: Intracellular trafficking of Gag and Env proteins and their interactions modulate pseudotyping of retroviruses. J Virol 2004, 78:7153-7164.

55. Grigorov B, Arcanger F, Roingeard P, Darlix JL, Muriaux D: Assembly of Infectious HIV-I in Human Epithelial and T-Lymphoblastic Cell Lines. J Mol Biol 2006, 359:848-862.

56. Taylor GM, Sanders DA: Structural criteria for regulation of membrane fusion and virion incorporation by the murine leukemia virus TM cytoplasmic domain. Virology 2003, 3 1 2:295-305.

57. Song C, Dubay SR, Hunter E: A tyrosine motif in the cytoplasmic domain of mason-pfizer monkey virus is essential for the incorporation of glycoprotein into virions. J Virol 2003, 77:5192-5200.

58. Weclewicz K, Ekstrom M, Kristensson K, Garoff H: Specific interactions between retrovirus Env and Gag proteins in rat neurons. J Virol 1998, 72:2832-2845. 
59. Page LJ, Robinson MS: Targeting signals and subunit interactions in coated vesicle adaptor complexes. J Cell Biol 1995, | 3 1:619-630.

Publish with Bio Med Central and every scientist can read your work free of charge

"BioMed Central will be the most significant development for disseminating the results of biomedical research in our lifetime. " Sir Paul Nurse, Cancer Research UK

Your research papers will be:

- available free of charge to the entire biomedical community

- peer reviewed and published immediately upon acceptance

- cited in PubMed and archived on PubMed Central

- yours - you keep the copyright
BioMedcentral 